\title{
The First-Order Approach to Merger Analysis*
}

\author{
Sonia Jaffe $\quad$ E. Glen Weyl ${ }^{\S}$
}

December 31, 2011

\begin{abstract}
Using only information local to the pre-merger equilibrium, we derive approximations of the expected changes in prices and welfare generated by a merger. We extend the pricing pressure approach of recent work to allow for non-Bertrand conduct, adjusting the diversion ratio and incorporating the change in anticipated accommodation. To convert pricing pressures into quantitative estimates of price changes, we multiply them by the merger pass-through matrix, which is close under conditions we specify to the pre-merger rate at which cost increases are passed through to prices. Weighting the price changes by quantities gives the change in consumer surplus.
\end{abstract}

How should we predict the unilateral impact of a merger on prices and welfare? The United States and United Kingdom horizontal merger guidelines released last year incorporate an approach based on the work of Werden (1996), Farrell and Shapiro (2010a) and others that uses information local to pre-merger prices to indicate the directional impacts of the mergers. This "first-order" approach to merger analysis (FOAM) is admirable for adopting both the simplicity and transparency of approaches based on market definition and the firm grounding in formal economics of market simulations. This paper takes this strategy a step further, attempting to incorporate the remaining strengths of alternative approaches: the quantitative precision of merger simulation and the agnosticism about market conduct and cost structures embodied in market definition. We show that FOAM, thus modified, provides

${ }^{*}$ We could not have written this paper without the encouragement and guidance of Joe Farrell and Carl Shapiro. We are also grateful to Dennis Carlton, Michal Fabinger Scott Duke Kominers, Serge Moresi, Markus Reisinger, Steve Salop, Dick Schmalensee, Greg Werden and seminar/session participants at the United Kingdom Competition Commission, the UK Office of Fair Trading, the European Union Directorate General for Competition, the Toulouse School of Economics, the Federal Communications Commission, RBB Economics, Harvard University, the University of California, Los Angeles, Compass Lexecon, the 9th Annual International Industrial Organization Conference, and the 4th Annual Searle Research Symposium on Antitrust Economics and Competition Policy. We particularly appreciate excellent discussions by Cory Capps and Kai-Uwe Kuhn. Jaffe acknowledges the support of a National Science Foundation Graduate Research Fellowship and a Terence M. Considine Fellowship in Law and Economics. Weyl acknowledges the support of the Milton Fund and the Harvard Real Estate Academic Initiative in making possible the outstanding research assistance of Toan Phan and Rui Wang. All errors are our own.

${ }^{\ddagger}$ Department of Economics, Harvard University, Graduate Student Office, Littauer Center, 1805 Cambridge Street, Cambridge MA 02138, sjaffe@fas.harvard.edu

${ }^{\S}$ Department of Economics, University of Chicago, 1126 E. 59th Street, Chicago IL, 60637, weyl@uchicago.edu 
a simple and general framework for predicting the impact on prices, as well as consumer and social surplus, of a merger based on information local to the pre-merger equilibrium.

The logic of the approach is intuitive: when companies A and B merge, company A (and similarly, B) has an additional opportunity cost of selling its products: it now internalizes the loss of profitable sales by company B that occurs when company A lowers its price. This per-unit opportunity cost equals the value of the sales diverted from B for each (marginal) sale by $A$ : the fraction of sales gained by A that are cannibalized from B (typically called the diversion ratio), multiplied by the profit-value of those sales (firm B's mark-up). This quantity, typically called "Upward Pricing Pressure" (UPP), is discussed explicitly in the new guidelines as being critical to determining merger effects; Werden (1996) and Farrell and Shapiro (2010a) advocate using thresholds for UPP to determine merger approval. ${ }^{1}$

However, some objections have been raised against the use of UPP:

1. Coate and Simons (2009) object to its near-universal assumption of Nash-in-prices (Bertrand) competition and its reliance, in some settings, on constant marginal costs.

2. Schmalensee (2009) and Hausman et al. (2010) are skeptical of its assumption of default efficiencies and argue that providing only a directional indication of price effects is insufficient.

3. Carlton (2010) emphasizes the difficulty of applying the UPP approach to mergers between multi-product firms.

While many of these critiques apply to one or all available alternative approaches, there is clearly room for improvement; this paper attempts to address these issues. We consider an extension of Telser (1972)'s general, single-strategic-variable-per-product oligopoly model, formulated in terms of prices (rather than quantities) and allowing for multi-product firms. As Telser shows, this encompasses most standard static oligopoly models - including Nashin-Prices (Betrand), Nash-in-Quantities (Cournot) and most supply function equilibrium and conjectural variations models - by including non-price behavior in anticipated reactions by other firms. In this context we derive formulae to predict the impact of a merger on prices, and thus also on consumer surplus, profits and social surplus, based on information local to the pre-merger equilibrium. We show that as long as the merger's effects on prices are small and the supply and demand system is sufficiently smooth, its approximate impact on consumer surplus takes the form

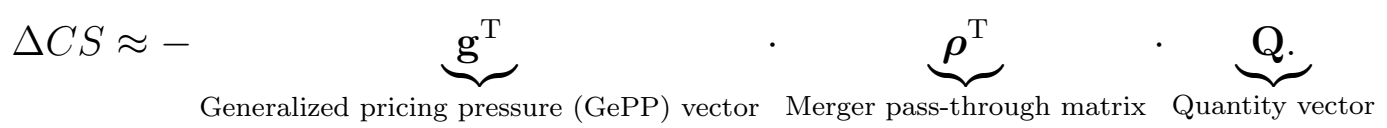

The first term, $\mathbf{g}$, is the Generalized Pricing Pressure (GePP), which generalizes UPP to allow for non-Bertrand conduct and general cost systems. Developed and explained more

\footnotetext{
${ }^{1}$ As the US guidelines put it, "[T]he Agencies may seek to quantify the extent of direct competition between a product sold by one merging firm and a second product sold by the other merging firm by estimating the diversion ratio from the first product to the second product" (United States Department of Justice and Federal Trade Commission, 2010). Werden actually advocates the use of a modified version of UPP, the "compensating marginal cost reductions" that we discuss in Subsection VI.A below.
} 
fully in Section II, GePP is a vector that has zeros for all non-merging firms and - in the case when single product firms 1 and 2 merge - a first entry of the form

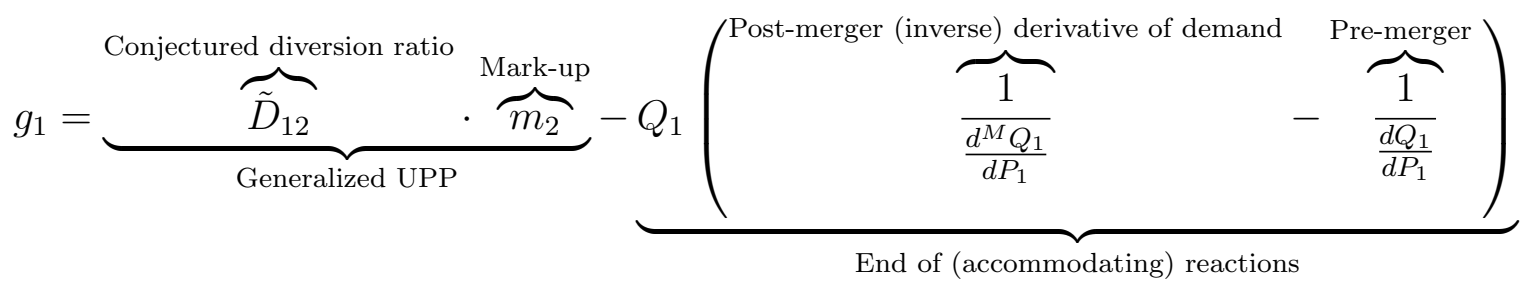

and an analogous second entry. The first term in equation (2) generalizes the basic Bertrand UPP logic by replacing the Bertrand diversion ratio, $D_{12}$ with the anticipated diversion ratio $\tilde{D}_{12}$. This is the diversion ratio from good 1 to good 2 (the fraction of a unit of good 2 that goes unsold when one more unit of good 1 is sold) when the impetus for the change in sales is a reduction in the price of good 1 holding fixed the price of good 2 but allowing all other prices to adjust as they are expected to by the merged firm. ${ }^{2}$ The price of good 2 is now held fixed because it has become, as a result of the merger, one of the quantities over which the merged firm optimizes. The second term in (2) is the quantity of good 1 multiplied by the change induced by the merger in the inverse of the slope of demand: now that the firms are merged, firm 1 no longer anticipates a reaction from firm 2 and thus expects the elasticity of its own demand to be higher (assuming accommodation pre-merger).

Anticipated accommodating reactions, arising from the true strategic variable being something (like quantities) other than price or from non-Nash behavior, have two effects. First, they increase the (conjectured) diversion ratio, as they both reduce the number of sales lost by firm 1 and increase those gained by firm 2, whose price is held fixed. Second, they increase the end of accommodating reactions term as the larger are such reactions the more impact their end has on the elasticity of demand. Which of these effects dominates will depend on whether anticipated accommodation between the merging firms and other firms in the industry (first effect) or accommodation between the merging partners (second effect) is stronger. Thus, as we illustrate by example in Subsection II.C, the size of GePP may not differ as much across alternative conduct assumptions as it might at first appear. Thus GePP under assumptions (such as consistent conjectures) that make identification easier can approximate GePP under other (possibly more realistic) assumptions.

The second term in equation (1), $\boldsymbol{\rho}$, is the merger pass-through matrix, the rate at which the changes in opportunity cost, the GePP, created by the merger are passed through to changes in prices. As we show in Section III, this quantity, which is a function of local second-order properties of the demand and cost systems, converts GePP into a quantitative approximation of the price effects of the merger. In Section IV we argue that, as confirmed by recent empirical work (Cheung, 2011), in many relevant cases merger pass-through is close to both pre-merger and post-merger pass-through, reconciling divergent strains in recent literature on the relevant pass-through rate. In some special cases, exact merger pass-through may be identified from pre-merger pass-through.

The calculated price changes for various goods can be put in a common denominator of consumer surplus by multiplying by the quantity vector $\mathbf{Q}$, as we discuss in Section V. A

\footnotetext{
${ }^{2}$ We follow the convention in the literature of treating the diversion ratio for substitutes as a positive number - the negative of the ratio of the changes in quantities in the single-product firm case.
} 
similar approach may be used to estimate social surplus impacts. Furthermore, this broad approach allows for the incorporation of impacts of mergers on consumer welfare not directly mediated by prices, such as changes in network size or product quality.

Section VI discusses extensions and practical implications of our framework, including the incorporation of marginal cost efficiencies, ways to simplify the formula given time and resource constraints and some commentary on how our formula and broader approach may be applied for policy and future research. Our conclusion in Section VII discusses directions for future research. A companion policy piece (Jaffe and Weyl, 2011) proposes a few potential reforms to the merger guidelines based on our analysis.

\section{Background}

During the 1970's the "Chicago School" of law and economics, culminating in Posner (1976)'s treatise on antitrust, helped raise the importance of formal economics in antitrust analysis. The 1982 U.S. Merger Guidelines (United States Department of Justice and Federal Trade Commission, 1982) reflected this growing influence in its move towards more detailed quantitative measures in the delineation of, and measurement of concentration within, antitrust product markets. These standards began with techniques based on market definition and Herfindahl (1950)-Hirschman (1945) Index (HHI) calculations; they were based on Stigler (1964)'s construction of a model in which the likelihood of collusion is mediated by HHI. However, emphasis during the late 1970's and 1980's on the differentiated nature of most product markets led to increasing concern (Werden, 1982) with the unilateral (non-cooperative) effects of mergers. ${ }^{3}$ Farrell and Shapiro (1990) challenged the relationship between market definition and the unilateral harms from mergers in the basic undifferentiated Cournot models. ${ }^{4}$ Thus, many economists have argued for approaches to merger analysis based more explicitly on differentiated product models. ${ }^{5}$

To help supply this need, Werden and Froeb (1994) proposed a logit demand system, which made merger simulation techniques practical for policy analysis. During the 1990's merger simulation achieved widespread success in academic circles, exploiting the advances in techniques for demand estimation pioneered by Berry et al. (1995), and culminating in the seminal analysis of Nevo (2000). However, Shapiro (1996) and Crooke et al. (1999) argued that the effects of mergers predicted by simulations could differ by an order of magnitude or more based on properties of the curvature of demand not typically measured empirically.

To address this concern, Werden (1996) pioneered FOAM by arguing that the "compensating marginal cost reductions" necessary to offset the anticompetitive effects of a merger could be calculated from first-order properties of the demand system. ${ }^{6}$ In particular, such

\footnotetext{
${ }^{3}$ Formal economic analysis of such unilateral effect began with the pioneering theoretical analysis of Werden (1982), Deneckere and Davidson (1985) and Levy and Reitzes (1992) in the context of differentiated products industries with symmetric firms and Farrell and Shapiro (1990) in homogeneous products industries with heterogeneous firms. Empirical work began with Baker and Bresnahan (1985)'s application of the Bresnahan (1981) consistent conjectures paradigm to the estimation of merger effects. The 1992 Guidelines' primary emphasis on unilateral effects officially recognized this shifting focus.

${ }^{4}$ However, Werden (1991) provides a provocative counterpoint.

${ }^{5}$ See Kaplow (2010) for a good summary of these arguments.

${ }^{6}$ As with the first-order approach to principal agent problems pioneered by Mirrlees (1971), FOAM seeks
} 
efficiencies would have to offset the change in first-order conditions created by the new opportunity cost of a sale due to the diversion from a product of a merger partner. This approach is computationally simple and transparent. Additionally, Shapiro (1996) observed that, regardless of functional form, merger effects appeared to be increasing in this "value of diverted sales" that has come be known as "Upward Pricing Pressure" (UPP). Building on this work, antitrust officials in the United Kingdom, led by Peter Davis and Chris Walters, began to use UPP to evaluate mergers (Walters, 2007).

Froeb et al. (2005) noted that functional forms implying higher pass-through rates of merger efficiencies were closely connected to those generating large anticompetitive merger effects. They proposed an approach, based on Newton's method, for conducting merger simulations in a computationally simpler manner whose first iteration also only required information local to pre-merger prices. Building on the pioneering practical work in the UK and theoretical analysis of Froeb et al., Farrell and Shapiro (2010a,b) translated these ideas into intuitive and widely accessible economic terms; they argued that after subtracting efficiencies from UPP the sign would indicate the direction of merger effects and put forward the measurement of UPP as a practical policy proposal for the evaluation of mergers. Under the leadership of Farrell and Shapiro, UPP was incorporated into the 2010 Guidelines (United States Department of Justice and Federal Trade Commission, 2010) released this past fall. The UK followed close behind with an even more explicit incorporation of UPP (Commission and of Fair Trading, 2010); the European Union is also considering revising its merger guidelines. The agencies' increased openness (Shapiro, 2010) to a range of simple tools with firm economic grounding has sharpened the focus on the appropriateness of FOAM as a policy proposal and its soundness as a theoretical construct. Competition agencies have also showed an increasing interest in broadening the scope of analysis, as exemplified by the recent Office of Fair Trading-comissioned report on the role of conjectural variations in merger policy (Majumdar et al., 2011).

\section{Generalized Pricing Pressure}

In this section we adapt Telser (1972)'s oligopoly model to derive a formula, Generalized Pricing Pressure (GePP), for the changes in pricing incentives firms face post-merger. We then explore two examples and one general result illustrating how the formula plays out in the more specific cases of Bertrand, Cournot and consistent conjectures. We also consider an example that explores how the degree of accommodating reaction affects the size of GePP. ${ }^{7}$ Because most of the paper studies the multi-product case in which nearly all objects are multi-dimensional, we henceforth bold neither vectors nor matrices.

to analyze seemingly global and potentially discrete phenomena using local information. Our paper is similar to Rogerson (1985) in aiming to shore up the foundation for powerful but incompletely formalized techniques of previous work.

${ }^{7}$ An extensions of the model to incorporate cost efficiencies is left to Subsection VI.A. 


\section{A The general model}

Consider a market with $N$ firms denoted $i=(1, \ldots, n)$. Firm $i$ produces $m_{i}$ goods, and chooses a vector of prices $P_{i}=\left(P_{i 1}, P_{i 2}, \ldots, P_{i m_{i}}\right)$ from a $\mathbb{R}^{m_{i}}{ }^{8}$ Following Telser (1972), we permit each firm to conjecture reactions by other firms: changes in other firms' strategies in response to a change in its own. This formulation is useful for two distinct purposes. First, it allows us to nest, as a special case, static oligopoly models where firms have a strategic variable other than price, such as quantity or a supply function shifter. Other firms' nonprice behavior is incorporated into a firm's conjectures about those firms' reactions to its price change. For example, as we illustrate in Subsection C below, Cournot competition is represented by a firm conjecturing that when it raises its price, other firms' will raise their prices so as to hold fixed the their quantities. This formulation encompasses many strategic contexts, but does restrict each firm to have a single strategic variable per product, as in Werden and Froeb (2008). ${ }^{9}$

Second, these conjectured reactions allow for the possibility of non-static Nash behavior in the spirit of Bowley (1924)'s conjectural variations. Despite their absence from the mainstream of industrial organization empirics and theory since the 1980's, recently there has been a resurgence in theoretical (Dockner, 1992; Cabral, 1995), empirical (Nevo, 1998; Ciliberto and Williams, 2010) and policy (Majumdar et al., 2011) interest in such conjectural variations as a useful reduced form for the complexities of dynamic models of competition.

These conjectures are modeled by letting a firm believe that when it changes its prices, $P_{i}$, its competitors will change their prices, $P_{-i}$, by $\frac{\partial P_{-i}}{\partial P_{i}}{ }^{10}$ Therefore, the total effect of a change in own price on a vector of interest is the sum of the direct (partial) effect and the

indirect effect working through the effect on others' strategies: $\frac{d A}{d P_{i}} \equiv \frac{\partial A}{\partial P_{i}}+\left(\frac{\partial A}{\partial P_{-i}}\right)^{\mathrm{T}} \frac{\partial P_{-i}}{\partial P_{i}}$. In the case of a Bertrand equilibrium, we have $\frac{d A}{d P_{i}}=\frac{\partial A}{\partial P_{i}}$ since $\frac{\partial P_{-i}}{\partial P_{i}}=0$.

\section{Pre-merger}

Firm $i$ 's profit $\pi_{i}$ depends on both its price vector and its competitors' prices:

$$
\pi_{i}=P_{i}^{\mathrm{T}} Q_{i}(P)-C_{i}\left(Q_{i}(P)\right)
$$

where $C$ and $Q$ are the cost and demand functions. For brevity we write $Q_{i}$ for $Q_{i}(P)$ and $\mathrm{mc}_{i}$ for the vector of marginal costs. The firm's vector of first-order conditions pre-merger

\footnotetext{
${ }^{8}$ In an earlier version of this paper we considered the analysis for the case where any strategy (such as quantity) being chosen. This more general analysis is available on request.

${ }^{9}$ We thus rule out changes in the non-price determining characteristics of products as considered in the literature on product repositioning (Mazzeo, 2002; Gandhi et al., 2008). See Section V for a discussion of how merger effects on non-price characteristics can be incorporated into our framework. See Telser (1972) for more details of the range of models that are special cases of this framework.

${ }^{10}$ Throughout the paper we use the notation $\frac{\partial}{\partial}$ to refer to the Jacobian, $\frac{\partial A}{\partial B} \equiv\left(\begin{array}{ccc}\frac{\partial A_{1}}{\partial B_{1}} & \cdots & \frac{\partial A_{1}}{\partial B_{n}} \\ \vdots & \ddots & \vdots \\ \frac{\partial \dot{A}_{n}}{\partial B_{1}} & \cdots & \frac{\partial A_{n}}{\partial B_{n}}\end{array}\right)$.
} 
can be written as:

$$
f_{i}\left(P^{*}\right) \equiv \underbrace{-\left(\frac{d Q_{i}^{\mathrm{T}}}{d P_{i}}\right)^{-1} Q_{i}}_{\text {Multiproduct inverse hazard rate/Cournot distortion }}-\underbrace{\left(P_{i}-\mathrm{mc}_{i}\right)}_{\text {Mark-up }}=0,
$$

This formula is a natural extension of the standard, single-product oligopoly first-order condition: the mark-up on each product is equated to the matrix analog of the partial inverse hazard rate or Cournot distortion. With a single-product Bertrand this is the partial inverse hazard rate of demand, $\frac{Q_{i}}{\partial Q_{i}}$; for the multi-product generalization here is $\left(\frac{\partial Q_{i}}{\partial P_{i}}\right)^{-1} Q_{i}$, the inverse of the Slutsky matrix limited to the firm's products multiplied by that firm's quantities.

\section{B Incentives created by a merger}

In studying the impact of a merger on firms' incentives, it is useful to define a couple terms.

Definition 1. If firms $i$ and $j$ merge, the post-merger diversion ratio is

$$
\tilde{D}_{i j} \equiv-\left(\frac{d^{M} Q_{i}{ }^{-1}}{d P_{i}}\right)^{T} \frac{d^{M} Q_{j}{ }^{T}}{d P_{i}},
$$

where $\frac{d^{M} Q_{k}}{d P_{i}}=\frac{\partial Q_{k}}{\partial P_{i}}+\frac{\partial Q_{k}}{\partial P_{-i j}} \frac{\partial P_{-i j}}{\partial P_{i}}$, which holds fixed the merging partner's prices.

The relevant diversion ratios are the matrix ratio of the quantity (anticipated to be) gained by the former rival's products to that (anticipated to be) lost by one's own products as a result of a change in price, holding fixed the strategy of the merger partner and allowing all other strategies to adjust as they are expected to in equilibrium.

This construction allow us to define a generalization of UPP in a simple manner.

Definition 2. Let a pre-merger equilibrium be defined by $f\left(P^{*}\right)=0$ and a post-merger equilibrium be defined by $h\left(P^{M}\right)=0$, where $f$ and $h$ are normalized to be quasi-linear in marginal cost (and price). Then we define $g\left(P^{*}\right) \equiv h\left(P^{*}\right)-f\left(P^{*}\right)$ to be the Generalized Pricing Pressure (GePP) created by the merger.

Thus GePP is the change in the first-order condition at the pre-merger strategies. It holds fixed the firms' strategy space and conjectures about other firms' reactions, thus capturing only the unilateral effects of a merger. The value of GePP is given in the following proposition.

Proposition 1. The GePP on firm $i$ generated by a merger between firms $i$ and $j$ is $g_{i}\left(P^{*}\right)$ where $P^{*}$ is the pre-merger equilibrium price vector and

$$
g_{i}(P)=\tilde{D}_{i j}\left(P_{j}-m c_{j}\right)-\Delta\left(\left({\frac{d Q_{i}}{d P_{i}}}^{-1}\right)^{T}\right) Q_{i} .
$$


Here $\Delta(\cdot)$ denotes the change from pre- to post-merger value of its argument; the change is due to the merger partner's strategy no longer reacting. ${ }^{11}$

Proof. See Appendix A.

The first term of equation (3) is the change in firm $j$ 's profits induced by a sale by firm $i$ (caused by changing firm $i$ 's price): the quantity firm $j$ gains for each unit lost by firm $i$ 's product times the value of that unit. The second term is the change in firm $i$ 's marginal profit due to the end of accommodating reactions: once the firms have merged, the firm no longer anticipates an accommodating reaction from its merger partner.

\section{Specific Contexts and Examples}

As further illustration, we now explore the model under a few common equilibrium concepts. The formulae for Bertrand, Cournot and consistent conjectures are below.

\section{Bertrand}

In the case of Bertrand, the expected accommodating reactions are zero, so GePP trivially simplifies to the standard (multi-product) UPP formula:

$$
g_{i}(P)=-\left(\frac{\partial Q_{i}^{\mathrm{T}}}{\partial P_{i}}\right)^{-1}\left(\frac{\partial Q_{j}^{\mathrm{T}}}{\partial P_{i}}\right)\left(P_{j}-\mathrm{mc}_{j}\right) .
$$

To help clarify, we now consider the explicit computation of GePP with two symmetric, multiproduct firms with constant marginal cost playing Bertrand against linear demand who then merge to (residual) monopoly. ${ }^{12}$

Example 1. Suppose that two symmetric, multiproduct firms 1 and 2 with constant marginal cost vector c face Slutsky symmetric demand system

$$
\left[\begin{array}{l}
Q_{1} \\
Q_{2}
\end{array}\right]=\left[\begin{array}{c}
A \\
A
\end{array}\right]-\left[\begin{array}{ll}
B_{o} & B_{x} \\
B_{x} & B_{o}
\end{array}\right]\left[\begin{array}{l}
P_{1} \\
P_{2}
\end{array}\right] .
$$

Profits prior to the merger for either firm $i$ are $\left(P_{i}-c_{i}\right)^{T} Q_{i}=\left(P_{i}-c_{i}\right)^{T}\left(A-B_{o} P_{i}-B_{x} P_{-i}\right)$ and thus, by the matrix product rule, the first-order condition is

$$
0=A-B_{o} P_{i}-B_{x} P_{-i}-B_{o}\left(P_{i}-c\right) \Longleftrightarrow 2 B_{o} P_{i}+B_{x} P_{-i}=A+B_{o} c,
$$

but, if we solve for a symmetric equilibrium, we can drop the subscripts on the price vectors and the equation becomes

$$
\left(2 B_{o}+B_{x}\right) P=A+B_{o} c_{i} \Longleftrightarrow P^{0}=\left(2 B_{o}+B_{x}\right)^{-1}\left(A+B_{o} c\right) .
$$

\footnotetext{
${ }^{11}$ Note that in the single-product firm case this is exactly equation (2) from the introduction.

${ }^{12}$ Note that we have criticized the plausibility of this demand system in other work (Jaffe and Weyl, 2010). We rely on it here not for realism but rather because it nicely illustrates both the potential accuracy of the approximation and how one may compute our formula in a specific example.
} 
Thus the pre-merger mark-up is

$$
\left(2 B_{o}+B_{x}\right)^{-1}\left(A+B_{o} c\right)-c=\left(2 B_{o}+B_{x}\right)^{-1}\left[A-\left(B_{o}+B_{x}\right) c\right] .
$$

From the above formula the diversion ratio is just $-B_{o}^{-1} B_{x}$. Thus the GePP on both firms is

$$
-B_{o}^{-1} B_{x}\left(2 B_{o}+B_{x}\right)^{-1}\left[A-\left(B_{o}+B_{x}\right) c\right] .
$$

\section{Cournot}

A general version of the formula for Cournot is appears in Appendix B. Here we focus on a simple example of differentiated Cournot competition which illustrates perhaps more clearly how the Cournot model fits as a special case of our analysis.

Example 2. Consider two symmetric, single-product firms facing a general demand system at a symmetric, Cournot equilibrium. The Slutsky matrix is both symmetric and persymmetric (symmetric about its anti-diagonal) and thus without loss of generality may be specified as

$$
\frac{\partial Q}{\partial P}=\left[\begin{array}{cc}
-(E+\sigma) & \sigma \\
\sigma & -(E+\sigma)
\end{array}\right]
$$

where $E, \sigma>0$ as the goods are substitutes and demand is downward sloping when both prices rise by the same amount. To calculate $\frac{d P_{-i}}{d P_{i}}$ we use the chain rule and the fact that under Cournot

$$
0=\frac{d Q_{-i}}{d P_{i}}=\frac{\partial Q_{-i}}{\partial P_{i}}+\frac{\partial Q_{-i}}{\partial P_{-i}} \frac{d P_{-i}}{d P_{i}}=\sigma-(E+\sigma) \frac{d P_{-i}}{d P_{i}} \Longleftrightarrow \frac{d P_{-i}}{d P_{i}}=\frac{\sigma}{E+\sigma} .
$$

Prior to the merger, firms price according to the logic of Subsection II.A. We drop all subscripts given symmetry:

$$
P-M C=-\frac{Q}{\frac{\partial Q_{i}}{\partial P_{i}}+\frac{\partial Q_{i}}{\partial P_{-i}} \frac{d P_{-i}}{P_{i}}}=-\frac{Q}{-(E+\sigma)+\frac{\sigma^{2}}{E+\sigma}}=\frac{Q(E+\sigma)}{(E+\sigma)^{2}-\sigma^{2}}=\frac{Q(E+\sigma)}{2(1+\sigma) E} .
$$

The appropriate diversion ratio is that holding fixed the price of the merger partner and is thus simply the Bertrand diversion ratio $\frac{\sigma}{E+\sigma}$. After the merger, a firm's market power is now just the Bertrand market power $\frac{Q}{E+\sigma}$. Thus the end of accommodation reactions term is

$$
\frac{Q(E+\sigma)}{2(1+\sigma) E}-\frac{Q}{E+\sigma}=Q \frac{(E+\sigma)^{2}-2 E-2 E \sigma}{2(1+\sigma)(E+\sigma) E}=Q \frac{E(1-2 E)+\sigma^{2}}{2(1+\sigma)(E+\sigma) E} .
$$

Thus GePP on each product is

$$
\frac{\sigma}{E+\sigma} \frac{Q(E+\sigma)}{2(1+\sigma) E}-Q \frac{E(1-2 E)+\sigma^{2}}{2(1+\sigma)(E+\sigma) E}=\frac{E(1+\sigma-2 E)}{2(1+\sigma)(E+\sigma) E} .
$$

Note that as the products become undifferentiated $(\sigma \rightarrow \infty)$ this converges to 0 as the largest power of $\sigma$ in the numerator is 1 while in the denominator it is two. This seems to indicate that a merger-to-monopoly in undifferentiated Cournot causes no increase in prices, which is clearly absurd. The problem is that, as we show in Appendix B, as the products become undifferentiated, the pass-through by which the GePP must be multiplied to obtain our approximation also explodes. This is case thus provides one reason why considering pass-through, and not just pricing pressure, is in many cases crucial. 


\section{Consistent Conjectures}

Bresnahan (1981) proposed that to tie down firms' beliefs about other firms' reactions one should require that they be consistent with what actually occurs when a firm is induced by a cost shock to change its prices; that is $\frac{d P_{k}}{d P_{i}}=\frac{d P_{k}}{d t_{i}}\left(\frac{d P_{i}}{d t_{i}}\right)^{-1}$ where $k \neq i$ is any other firm and $t^{i}$ is a vector of shifters of only firm $i$ 's marginal costs (such as product specific quantity taxes).

There has been long debate about the attractiveness of consistent conjectures as a theoretical concept, but it is clear both by application (Baker and Bresnahan, 1985, 1988) and from theory (Weyl, 2009), that it has practical benefits: it offers simple procedures for empirically estimating the relevant elasticities with fewer instruments than are needed under Bertrand competition. The following proposition provides a formalization of this folk intuition in the merger context.

Proposition 2. Suppose an exogenous vector of variables $x$ of dimension $m_{1}+m_{2}$ (the total number of products of the two merging firms) has the property that $\frac{\partial f_{k}}{\partial x}=0$ for all $k \neq 1,2$ while the matrix formed by $\left(\begin{array}{c}\frac{d f_{1}}{d x} \\ \frac{d f_{2}}{d x}\end{array}\right)$ is non-singular. Then observing $\frac{d P_{1}}{d x}, \frac{d P_{2}}{d x}, \frac{d Q_{1}}{d x}$ and $\frac{d Q_{2}}{d x}$ identifies $\frac{d Q_{1}}{d P_{1}}, \frac{d Q_{1}}{d P_{2}}, \frac{d Q_{2}}{d P_{1}}$ and $\frac{d Q_{2}}{d P_{2}}$ and thus $\tilde{D}_{12}, \frac{d^{M} Q_{1}}{d P_{1}}, \frac{d^{M} Q_{2}}{d P_{2}}$ and finally the Generalized Pricing Pressures, $g_{1}, g_{2}$, under consistent conjectures. The partial derivatives (i.e. $\frac{\partial Q_{1}}{\partial P_{2}}$ ) are not identified, so further variation is required to identify these parameters, which are necessary to calculate $\tilde{D}_{12}$ and the GePP under Bertrand.

Proof. See Appendix C.

This shows in a more abstract context the result that Baker and Bresnahan (1988) implicitly rely on in the case of linear demand: if conjectures are consistent then the relevant elasticity of demand for a single firm is that which would be observed in the data based on a cost shock to that firm alone. Under the Bertrand conduct, in order to predict the behavior of even a single firm, enough instruments must be available to hold fixed all other firms' prices (as they do not in equilibrium stay fixed in response to a single-firm cost shock), leading to the classic curse of dimensionality (Ackerberg et al., 2007) in empirical industrial organization. Under consistent conjectures only shocks to the firms whose incentives one wishes to identify are necessary.

\section{How much does accommodation matter?}

A natural concern here, is that, especially in differentiated product industries, it may be difficult to determine empirically (Nevo, 1998) or even grasp intuitively what conduct is appropriate. While for many questions this is a serious worry, it may not be as severe a problem for merger analysis since, as we discuss in the introduction, changes in the conduct (or solution concept) may have offsetting effects in the two terms of GePP. With more accommodating ("collusive") behavior the increased diversion ratio pushes GePP in the opposite direction as the increased change from the end of the merging partner's accommodating reactions. To illustrate this, and more broadly how GePP can be computed in specific models, we consider the role of conduct in two simple examples. 
Example 3. Consider a pre-merger symmetric industry with $n$ single-product firms playing a symmetric equilibrium, earning mark-up $m$, selling quantity $q$ each, with an aggregate (Bertrand) diversion ratio $D$ to the $n-1$ other firms in the industry. Each firm anticipates an increase in $\lambda$ by all other firms in response to a one unit local increase in their own price.

The first-order condition for a single firm requires that

$$
m=-\frac{q}{\frac{d Q_{i}}{d P_{i}}} .
$$

Prior to the merger, by symmetry $\frac{d Q_{i}}{d P_{i}}=\frac{\partial Q_{i}}{\partial P_{i}}+(n-1) \lambda \frac{\partial Q_{i}}{\partial P_{j}}$. But symmetry also implies that $\frac{\partial Q_{i}}{\partial P_{j}}=\frac{d Q_{j}}{d P_{i}}=-\frac{\partial Q_{i}}{\partial P_{i}} \frac{D}{n-1}$. Solving out we obtain

$$
\frac{\partial Q_{i}}{\partial P_{i}}=-\frac{q}{m(1-D \lambda)}
$$

Post-merger the price of the merger partner is held fixed rather than increasing by $\lambda$ in response to an increase in the firm's price. To see how this changes anticipated accommodation, note that the total pre-merger accommodation firm $i$ anticipates from each other firm is the effect coming through its impact on its merger partner and the effects holding fixed its merger partner's price. By symmetry, therefore, the post-merger symmetric increase in the $n-2$ remaining firms' prices in response to an increase in one of the partners' prices, $\tilde{\lambda}$, must satisfy

$\underbrace{\lambda}_{\text {pre-merger accommodation }}=\underbrace{\tilde{\lambda}}_{\text {holding fixed partner }}+\underbrace{\tilde{\lambda}}_{\text {partner's equilibrium effect holding } i \text { fixed equilibrium partner accommodation }}$,

by the chain rule. Thus $\tilde{\lambda}=\frac{\lambda}{1+\lambda}$. With these quantities in hand, we can calculate the relevant post-merger derivatives.

First consider $\frac{d^{M} Q_{1}}{d P_{1}}$. This is composed of the direct Slutsky effect and the indirect effect from the change in the $n-2$ non-merging firm prices:

$$
\frac{d^{M} Q_{1}}{d P_{1}}=\frac{\partial Q_{i}}{\partial P_{i}}+\tilde{\lambda} \frac{n-2}{n-1} \frac{\partial Q_{i}}{\partial Q_{j}}=\frac{\partial Q_{i}}{\partial P_{i}}\left(1-\tilde{\lambda} \frac{n-2}{n-1} D\right),
$$

while for the merger partner, firm 2, the sales gained are the direct diversion plus the indirect diversion from the $n-2$ non-merging firms' accommodation:

$$
\frac{d^{M} Q_{2}}{d P_{1}}=-\frac{\partial Q_{i}}{\partial P_{i}} \frac{D}{n-1}(1+\tilde{\lambda}[n-2])
$$

Thus,

$$
\tilde{D}_{12} \cdot m=\frac{\frac{D}{n-1}(1+\tilde{\lambda}[n-2])}{1-\tilde{\lambda} \frac{n-2}{n-1} D} m=\frac{D[1+\tilde{\lambda}(n-2)]}{(n-1)(1-\tilde{\lambda} D)+\tilde{\lambda} D} m
$$

while

$$
Q_{1}\left(\frac{1}{-\frac{d Q_{1}}{d P_{1}}}-\frac{1}{-\frac{d_{M} Q_{1}}{d P_{1}}}\right)=q\left(\frac{1}{\frac{q}{m}}-\frac{1-D \lambda}{\frac{q}{m}\left(1-\tilde{\lambda} \frac{n-2}{n-1} D\right)}\right)=D m \frac{(\lambda-\tilde{\lambda})(n-1)+\tilde{\lambda}}{(n-1)(1-\tilde{\lambda} D)+\tilde{\lambda} D}
$$


where the last step follows by some tedious and thus omitted algebra. Subtracting these two terms and using $\lambda-\tilde{\lambda}=\frac{\tilde{\lambda}}{1-\tilde{\lambda}}-\tilde{\lambda}=\frac{\tilde{\lambda}_{2}}{1-\tilde{\lambda}}$ yields

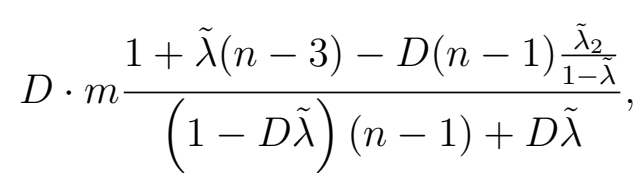

If we focus on the case where $\lambda$ and thus $\tilde{\lambda}$ are small so that we can ignore second-order terms, this simplifies to

$$
D \cdot m \frac{1+\tilde{\lambda}(n-3)}{(1-D \tilde{\lambda})(n-1)+D \tilde{\lambda}} .
$$

In analyzing (4), we begin by focusing on this approximate formula. Note that $\tilde{\lambda}$ is strictly increasing in $\lambda$. When $n=2$, we are considering a merger to monopoly, equation (4) is proportional to $1-\tilde{\lambda}$, which is clearly decreasing in $\lambda$. That is, as discussed above, if accommodation by the merger partner is the only issue, GePP declines with the degree of accommodation as Farrell and Shapiro (2010a) conjecture. However, when $n=3$ equation (4) is proportional to $\frac{1}{2-D \tilde{\lambda}}$ which is clearly increasing in $\lambda$. This effect gets stronger as $n \rightarrow \infty$; in the limit the expression is proportional to $\frac{\tilde{\lambda}}{1-D \tilde{\lambda}}$ which increases even more quickly in $\lambda$. Thus, in this basic example, "somewhere between" a merger to a monopoly and a merger by two firms within a triopoly the effect of accommodation on GePP switches from negative to positive.

It is easily verified that whenever the approximate formula is increasing in $\lambda$ (and $\lambda$ is positive) so is the exact expression, but that sometimes (when $\lambda$ is large enough) the exact expression is decreasing in $\lambda$ despite the approximate expression in the text being increasing. Thus the conclusion that GePP is may decrease in $\lambda$ so long as the number of firms is small enough is stronger in the exact case than in the approximate case.

By the same logic, in a non-symmetric industry, the strength of accommodation between merging firms relative to accommodation between each merging firm and the other firms in the industry matters. See Appendix D for an example illustrating this in a manner similar to Example 3.

\section{Price Changes}

GePP measures how much firm incentives shift when the firms merge. However, policy makers are typically interested in such shifts in incentives only insofar as they predict changes in prices. We extend the work of Chetty (2009) to show how a comparative static approach without a fully-estimated structural model can be used even to analyze structural changes such as mergers. If the change in incentives is small, the effect of a merger can be approximated the same way the effect of a tax would be, despite the fact that unlike with a tax we cannot imagine a merger "going to zero" to make our formula exact.

Our approach is simply to apply the appropriate envelope theorem, viewing the change in incentives created by the merger, $g$, as a vector of local changes in the equilibrium conditions; we then apply Taylor's Theorem for inverse functions to approximate the post-merger 
conditions around the pre-merger equilibrium. This, as with any comparative statics exercise, allows us both to derive an approximation to the effect of the merger based purely on local properties and get a bound on the error of the approximation based on the curvature and the size of the intervention. Theorem 1 gives our main result.

Theorem 1. Let $P^{0}$ be the pre-merger equilibrium price vector. If $f$ is the vector of premerger first-order conditions and $g$ is the vector of GePPs so $\frac{\partial f(P)}{\partial P}+\frac{\partial g(P)}{\partial P}$ is the Jacobian of the post-merger first-order condition and $(f+g)$ is invertible, then, to a first-order approximation,

$$
\Delta P=-\left.\left(\frac{\partial f(P)}{\partial P}+\frac{\partial g(P)}{\partial P}\right)^{-1}\right|_{P^{0}} g\left(P^{0}\right)
$$

Proof. Let $h(P)=f(P)+g(P)$, since $f\left(P^{0}\right)=0$, we have $h\left(P^{0}\right)=g\left(P^{0}\right) \equiv r$. We want to find $P^{M}$ (the post-merger price), such that $h\left(P^{M}\right)=0$. If $h$ is invertible, then

$$
\begin{aligned}
P^{M}-P^{0} & =h^{-1}(0)-h^{-1}(r)=\left.\frac{\partial h^{-1}}{\partial h}\right|_{r}(0-r)+O\left(\|r\|^{2}\right) \\
& \approx-\left.\left(\frac{\partial f(P)}{\partial P}+\frac{\partial g(P)}{\partial P}\right)^{-1}\right|_{P^{0}} g\left(P^{0}\right)
\end{aligned}
$$

which completes the proof.

As we show in Appendix E, the $i$ th entry of the error vector in equation (5) takes the form

$$
E_{i}=-\frac{1}{2} \sum_{j}\left[\left(\frac{\partial h}{\partial P}\right)^{-1}\right]_{i j} g^{\mathrm{T}}\left(P_{0}\right)\left(\frac{\partial h^{\mathrm{T}}}{\partial P}\right)^{-1}\left(D_{P}^{2} h_{j}\right)\left(\frac{\partial h}{\partial P}\right)^{-1} g\left(P_{0}\right),
$$

where $[A]_{i j}$ indicates the $i j$ element of matrix $A, D_{P}^{2} h_{j}$ indicates the Hessian of $h_{j}$ and the derivatives and Hessian are evaluated at some $P \in\left[P^{0}, P^{M}\right]$. This error is small whenever $g$ is small and the first-order conditions are not highly curved in the relevant range. ${ }^{13}$ Our approximation is equivalent, in the case of constant cost Bertrand conduct, to the first step of the Newton's method approach to merger simulation proposed by Froeb et al. (2005), though the justification is different. ${ }^{14}$

We think these conditions for accuracy are not too restrictive for two reasons:

1. First, mergers leading to large changes in incentives will typically, though not always, lead to large changes in a common direction. If these are great enough to indicate via a local analysis that a large, likely detrimental effect will occur, then that is a strong basis for skepticism about the social desirability of a merger. In such circumstances, precise estimates of price changes are less important, and any quantitative approach relying on pre-merger data will struggle equally.

\footnotetext{
${ }^{13}$ Since the curvature part of the error term is evaluated as some $\tilde{P} \in\left[P^{0}, P^{M}\right]$, the curvature of the post-merger first-order condition must be bounded over the range, not just at the pre- and post-merger equilibria.

${ }^{14}$ For example, the second step of their approach does not correspond to the second-order term that would be derived from our expansion, as theirs relies on non-local but first-order information while ours uses local, higher-order derivatives.
} 
2. Second, essentially all functional forms used in demand estimation are very smooth (have sharply bounded curvature of equilibrium conditions) and thus our approximation is highly precise for a fairly large range of merger impacts if these demand systems are correct. ${ }^{15}$ These conclusions were tentatively confirmed by Cheung (2011) in an empirical analysis of the US Airways-America West merger that found our approximation to be small compared to the statistical estimation error, even when the wrong (post-merger) pass-through rates were used.

To illustrate the application of our formula, we now return to the simple case we considered in Example 1.

Example 1 Continued. Post-merger, by the logic of Section II, first-order conditions are

$$
P-c=B_{o}^{-1} A-P-B_{o}^{-1} B_{x} P-B_{o}^{-1} B_{x}(P-c) \Longleftrightarrow 2\left(B_{o}+B_{x}\right) P=A+\left(B_{x}+B_{o}\right) c
$$

or

$$
P^{M}=\frac{1}{2}\left(B_{o}+B_{x}\right)^{-1}\left[A+\left(B_{x}+B_{o}\right) c\right] .
$$

Thus, repeatedly using the Slutsky symmetry of the $B$ matrices,

$$
\begin{gathered}
\Delta P=\frac{1}{2}\left(B_{o}+B_{x}\right)^{-1}\left[A+\left(B_{x}+B_{o}\right) c\right]-\left(2 B_{o}+B_{x}\right)^{-1}\left(A+B_{o} c\right)= \\
\frac{1}{2}\left[\left(B_{o}+B_{x}\right)\left(2 B_{o}+B_{x}\right)\right]^{-1}\left[\left(2 B_{o}+B_{x}\right) A+\left(2 B_{o}+B_{x}\right)\left(B_{o}+B_{x}\right) c-2\left(B_{o}+B_{x}\right) A-2\left(B_{o}+B_{x}\right) B_{o} c\right] \\
=\frac{1}{2}\left[\left(B_{o}+B_{x}\right)\left(2 B_{o}+B_{x}\right)\right]^{-1} B_{x}\left[-A+\left(B_{o}+B_{x}\right) c\right]
\end{gathered}
$$

On the other hand, we can compute our approximation. Taking the derivative of the postmerger first-order condition linear in cost with respect to $P_{i}$ yields $-2 I$, where $I$ is the identity matrix of appropriate size. Taking the derivative with respect to $P_{-i}$ gives $-2 B_{o}^{-1} B_{x}$, so that the merger pass-through is

$$
\frac{1}{2}\left[\begin{array}{cc}
I & B_{o}^{-1} B_{x} \\
B_{o}^{-1} B_{x} & I
\end{array}\right]^{-1}=\frac{1}{2}\left(I-B_{o}^{-1} B_{x} B_{o}^{-1} B_{x}\right)\left[\begin{array}{cc}
I & -B_{o}^{-1} B_{x} \\
-B_{o}^{-1} B_{x} & I
\end{array}\right] .
$$

Thus, plugging in our calculation from Example 1, our approximation is, again heavily using Slutsky symmetry,

$$
\begin{gathered}
\frac{1}{2}\left(I-B_{o}^{-1} B_{x} B_{o}^{-1} B_{x}\right)-B_{o}^{-1} B_{x}\left(2 B_{o}+B_{x}\right)^{-1}\left[A-\left(B_{o}+B_{x}\right) c\right]= \\
\frac{1}{2}\left[\left(B_{o}+B_{x}\right)\left(I-B_{o}^{-1} B_{x}\right)\right]^{-1}\left(I-B_{o}^{-1} B_{x}\right) B_{x}\left[-A+\left(B_{o}+B_{x}\right) c\right]= \\
=\frac{1}{2}\left[\left(B_{o}+B_{x}\right)\left(2 B_{o}+B_{x}\right)\right]^{-1} B_{x}\left[-A+\left(B_{o}+B_{x}\right) c\right] .
\end{gathered}
$$

This is identical to the expression in (6) and thus, in this case, our approximation is exact.

\footnotetext{
${ }^{15}$ Any method that tries to estimate merger effects from exclusively pre-merger data will struggle if the true demand system is not smooth.
} 
In this example, we focused on the case of symmetric two, pre-merger-Bertrand firms merging to monopoly while facing Slutsky symmetric demand in order to simplify notation and shorten calculations. However, our approximation formula remains exact so long has linear demand and linear conjectures are maintained: Slutsky symmetry, merger to monopoly and symmetry across firms are not required. A proof is available on request.

\section{Role of Pass-Through}

Over the past decade an increasing informal consensus among economists interested in mergers has suggested that pass-through rates play an important role in determining the magnitude of merger effects. This section discusses the relationship among different proposed pass-through rates in light of our analysis above, as well as the practical implications for identification of the relevant values.

Shapiro (1996) and Crooke et al. (1999) showed that demand forms with differing curvature, but the same local matrix of cross-price elasticities, might lead to simulated merger effects differing by an order of magnitude or more. Froeb et al. (2005) argued that the same assumptions about demand that tend to predict large pass-through of efficiencies also predict large anticompetitive merger effects, but did not emphasize whether it was the demand curvature or the pass-through itself that was crucial. They emphasized that post-merger pass-through rates, which they argued were relevant to the pass-through of efficiencies, might in principle differ greatly from pre-merger pass-through rates, though they do not provide examples of such divergences.

Weyl and Fabinger (2009) and Farrell and Shapiro (2010a) argued informally that because UPP is essentially the opportunity cost of sales created by the merger, multiplying it by the pre-merger pass-through rates should approximate merger effects. Farrell and Shapiro (2010b) and Kominers and Shapiro (2010) prove in the symmetric case that bounds on premerger pass-through, in conjunction with those on UPP, over the range between pre- and post-merger prices can be used to establish bounds on merger effects. However since they use a constant marginal cost framework under which pass-through and demand curvature are equivalent, it is not clear which is the crucial quantity. In the following section we reconcile this apparent conflict between pre- and post-merger pass-through rates as the crucial quantities, and resolve the ambiguity between pass-through and demand curvature.

\section{A Pre-merger, post-merger and merger pass-through}

Marginal costs enter quasi-linearly into the expression for $f_{i}$ for an individual firm $i$. That is $f_{i}(P)=\tilde{f}_{i}(P)+\mathrm{mc}_{i}(P)$ and thus if we were to impose on the firms a vector of quantity taxes $t$, the post-tax (but pre-merger) equilibrium would be characterized by

$$
f(P)+t=0
$$

so that by the implicit function theorem

$$
\frac{\partial P}{\partial t} \frac{\partial f}{\partial P}=-\mathcal{I}
$$


The pre-merger pass-through matrix is

$$
\rho_{\leftarrow} \equiv \frac{\partial P}{\partial t}=-\left(\frac{\partial f}{\partial P}\right)^{-1}
$$

After the merger between firm $i$ and firm $j$ takes place, the marginal cost of producing firm $i$ 's goods enters quasi-linearly, with a coefficient of 1 , into $h_{i}$ (its post-merger first-order conditions), but also enters $h_{j}$ quasi-linearly with a coefficient of $-\tilde{D}_{j i}$. This follows directly from the fact that, the GePP for $j$ includes the mark-up on good $i$ which depends (negatively) on the tax. Thus if we let

$$
K=\left(\begin{array}{cc}
1 & -\tilde{D}_{i j} \\
-\tilde{D}_{j i} & 1
\end{array}\right),
$$

then the post-merger and post-tax equilibrium is characterized by

$$
h(P)=-K t
$$

and thus the post-merger pass-through matrix is ${ }^{16}$

$$
\rho_{\rightarrow} \equiv \frac{\partial P}{\partial t}=-\left(\frac{\partial h}{\partial P}\right)^{-1} K
$$

Our result from the previous section is that $P^{M}-P^{0} \approx-\left(\frac{\partial h(P)}{\partial P}\right)^{-1} g\left(P^{0}\right)$. Thus, merger pass-through $-\left(\frac{\partial h}{\partial P}\right)^{-1}$ is not equal to pre-merger pass-through $-\left(\frac{\partial f}{\partial P}\right)^{-1}$ or post-merger passthrough $-\left(\frac{\partial h}{\partial P}\right)^{-1} K$; rather it relies on the curvature of the latter and the cost structure of the former. This is intuitive since the post-merger first-order conditions are relevant, but the opportunity costs are not physical costs so they enter directly, rather than distributed as post-merger marginal costs. ${ }^{17}$

For a graphical intuition on why the curvature is important, see Figure 1. The thick lines show the pre-merger profit in terms of price and the thin (blue) lines show the postmerger profits. The dotted lines result from a constant pas-through demand system with pass-through equal to .1, for the solid lines pass-through is .4. Costs are such that pre-merger both firms profits are maximized at the same optimal price $\left(p^{*} \approx 1.406\right)$. They also have the same GePP, as evidenced by the tangency of the solid and dotted thin (blue) lines at $p^{*}$. However the curvature of the profit functions is very different and the profit maximizing post-merger prices will be very different. For the dotted line, (pass-through=.1), the postmerger price is approximately 1.445 ; for the solid line (pass-through $=.4$ ), the post-merger

\footnotetext{
${ }^{16}$ The term with $\frac{\partial K}{\partial P} t$ drops out because the tax is zero to begin with.

${ }^{17}$ This connection between the merger pass-through and price changes is general, allowing for arbitrary conduct and cost functions. Thus, it appears that pass-through, rather than simply demand curvature, is a fundamental determinant of merger effects. In addition to aiding intuition, this is of practical relevance: pass-through rates are potentially observable, in the relevant market or in similar markets in the past. Moreover, ? provide a number of connections between pass-through rates and other potentially observable or intuitively meaningful quantities which may allow intelligent guesses about pass-through rates to be made on the basis of observable properties of industries. Though these connections apply only to pre- and postmerger pass-through, the following section discusses when and how pre-merger pass-through can be used to calculate or approximate merger pass-through.
} 
price is off the graph to the right. For demand systems with the same pre-merger price and same pricing pressure, differences in pass-through can have a big effect on the price change generated by a merger.

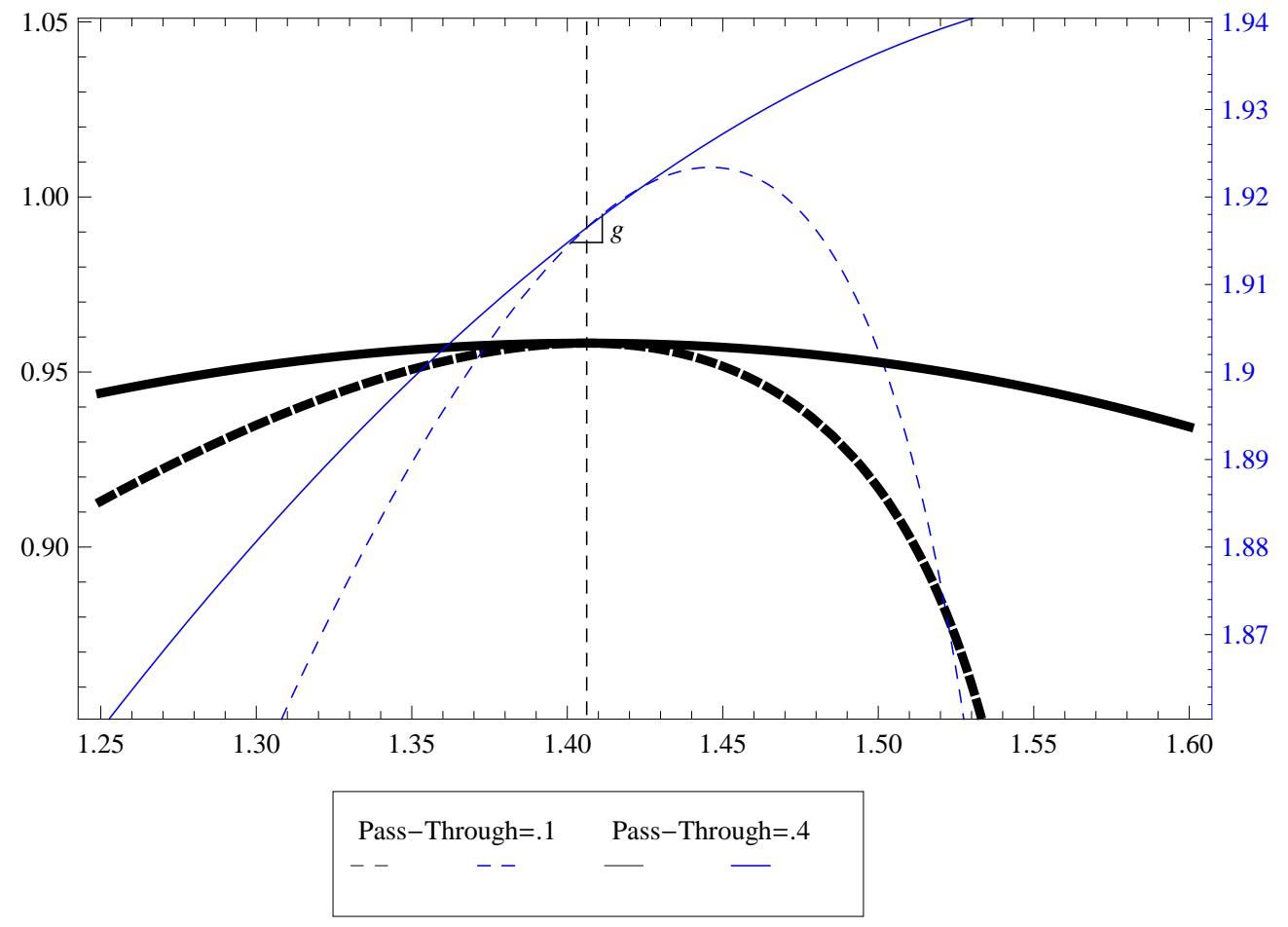

Figure 1: The effect of pricing pressure for low and high pass-through.

\section{B Calculation and approximation of merger pass-through}

\section{Identification}

When can we identify the merger pass-through from the pre-merger pass-through? Since $\frac{\partial f(P)}{\partial P}$ is equal to the negative inverse of the pass-through matrix, it is clearly calculable. ${ }^{18}$ In the case of two firms merging under Bertrand equilibrium, the pass-through matrix, along with the first derivatives of demand, can be used to calculate $\frac{\partial^{2} Q_{i}}{\partial P_{i}^{2}}, \frac{\partial^{2} Q_{i}}{\partial P_{i} \partial P_{j}}, \frac{\partial^{2} Q_{j}}{\partial P_{j} \partial P_{i}}$, and $\frac{\partial^{2} Q_{j}}{\partial P_{j}^{2}}$. If one assumes Slutzky symmetry $\left(\frac{\partial Q_{i}}{\partial P_{j}}=\frac{\partial Q_{j}}{\partial P_{i}}\right)$, then the other second derivatives are

$$
\frac{\partial^{2} Q_{j}}{\partial P_{i}^{2}}=\frac{\partial}{\partial P_{i}} \frac{\partial Q_{j}}{\partial P_{i}}=\frac{\partial}{\partial P_{i}} \frac{\partial Q_{i}}{\partial P_{j}}=\frac{\partial^{2} Q_{i}}{\partial P_{i} \partial P_{j}}
$$

and $\frac{\partial^{2} Q_{i}}{\partial P_{j}^{2}}=\frac{\partial^{2} Q_{j}}{\partial P_{i} \partial P_{j}}$, which are all that is needed to calculate $\frac{\partial g(P)}{\partial P}$. Since there is little intuition to be gained from the form of $\frac{\partial g(P)}{\partial P}$, we leave it to Appendix F. A similar procedure may be applied under Cournot competition.

\footnotetext{
${ }^{18}$ Note that because a block of an inverted matrix does not equal the inverse of the block, we also need pass-through rates of non-merging firms.
} 
In the case of more than two merging firms, derivatives of the form $\frac{\partial^{2} Q_{i}}{\partial P_{j} \partial P_{k}}$ are needed and cannot be calculated from observed pass-through rates and first derivatives unless one places restriction on the form of demand. A slightly more restrictive version of the horizontality assumption of Weyl and Fabinger (2009),

$$
Q_{i}(P)=h\left(p_{i}+\sum_{j \neq i} f_{j}\left(P_{j}\right)\right),
$$

is sufficient to calculate the necessary second partials. While it is only an approximation, and recent work suggests it may never be exactly consistent with discrete choice demand (Jaffe and Kominers, 2011), horizontality seems frequently to be a good approximation to demand in a discrete choice context (Gabaix et al., 2009; Quint, 2010).

In non-Nash equilibrium concepts, calculation becomes even more difficult. Consider the conjectural variation framework. The only way to avoid relying on firms' reports of what they conjecture $\frac{d P_{-i}}{d P_{i}}$ to be is to assume their conjectures are consistent along the lines of Bresnahan (1981)'s consistent conjectures. In that case, because there is no guarantee that Slutsky symmetry is satisfied by the relevant residual demand system, calculating the price changes requires a direct observation of the relevant second derivative of demand both when other prices adjust (which requires the derivative of the reaction function) and when they are held fixed. It is possible that a large number of instruments allowing for sufficient variation to identify these higher-order derivatives could be found, but it seems unlikely in practice.

\section{Approximation}

However, the difference between pre-merger and merger pass-through (and post-merger passthrough) may in fact be small. For our approximation to be valid, $g\left(P^{0}\right)$ and the curvature of the equilibrium conditions need to be jointly sufficiently "small". If $g\left(P^{0}\right)$ is small, then it seems likely that $\frac{\partial g\left(P^{0}\right)}{\partial P}$ would also be small and thus $\left(\frac{\partial h\left(P^{0}\right)}{\partial P}\right)^{-1}$ would be approximately $\left(\frac{\partial f\left(P^{0}\right)}{\partial P}\right)^{-1}$. If this were not the case, then while $g\left(P^{0}\right)$ is small, if $g(P)$ were evaluated at a relatively close price in the direction of maximal gradient rather than at $P^{0}$ it would then no longer be small. To the extent that the smallness of $g$ is "fragile" in this sense, it is unlikely to form a solid basis for using first-order approximations.

Thus, in many cases when the first-order approximation would be valid, the merger passthrough is approximately equal to pre-merger pass-through. Furthermore, if small diversion ratios, rather than other factors, cause $g\left(P^{0}\right)$ to be small, then post-merger pass-through will also be close to merger pass-through as $K$ will be close to the identity matrix. If a merger is likely to have a small impact on prices, then it is likely to have a small impact on pass-through rates and thus both pre- and post-merger pass-through rates will approximate merger passthrough. Of course, using merger pass-through is very likely to be more accurate than using pre- or post-merger pass-through. An extreme example of this effect is the undifferentiated limit of Cournot competition, where $\frac{\partial g}{\partial P}$ becomes large even though $g$ approaches 0 at the unstable symmetric point, as we discuss in Appendix B.

Nonetheless, the interpretation which views pre-, post- and merger pass-through as close to one another has a number of benefits, at least when products are reasonable differentiated. 
First, it is consistent with the apparent coincidence (Froeb et al., 2005) that demand forms that are known to give rise to high pre-merger pass-through rates also have been found to generate high pass-through of merger efficiencies (which are driven by post-merger passthrough) and large anti-competitive effects (which are proportional to merger pass-through). Second, it shows that the Froeb et al. and the Shapiro et al. logic are on some level consistent with one another: to the extent that either is valid as a way to approximate merger effects, they are likely to give similar answers. Third, it shows that using intuitions about passthrough rates to approximate the rate at which GePP is passed through to prices may be reasonable. Finally, it appears to be tentatively confirmed by the empirical study of Cheung (2011), who shows that using post-merger pass-through in place of merger pass-through leads to total approximation error smaller that statical estimation error in her application.

\section{Welfare Changes}

The changes in prices calculated in Section III can be converted into estimates of changes in consumer or social surplus. This is useful because we generally care about price changes only in so far as they affect welfare. This normative approach based on consumer or social surplus is concordant with a large body of economic and legal scholarship on the appropriate standards for antitrust policy. While there is still strong disagreement over whether consumer or social surplus is the appropriate standard to apply, there seems to be widespread agreement that one of these two, or some mixture of them, should be targeted (Farrell and Katz, 2006). Additionally, focusing on surplus allows for the analysis of mergers that affect multiple products where the changes in price may vary substantially. Also, to the extent that there is substantial uncertainty in the estimates of the relevant parameters, looking at welfare combines the confidence intervals (by plugging in different estimates to the forumulas) in the appropriate way to get the corresponding bounds on the metric that we ultimately care about. ${ }^{19}$

\section{Consumer Surplus}

First, consider consumer surplus in the evaluated market (ignoring externalities and potential cross-market effects of the price changes). To a first-order, the change in consumer surplus is, by the classic Jevons formula, just the sum across goods of the change in price times the quantity: $\triangle C S \approx-\Delta P^{\mathrm{T}} Q .{ }^{20}$ It becomes unit-free, as with any other price index, if it is normalized by the initial value of the price index $P^{\mathrm{T}} Q$ yielding $\Delta I_{C S} \approx-\frac{\Delta P^{\mathrm{T}} Q}{P^{\mathrm{T}} Q}$.

\section{Social Surplus}

Estimating the change in social surplus requires an estimate for the expected change in quantity. Multiplying the Slutzky matrix $\frac{\partial Q}{\partial P}$ by the estimated price changes gives a first-

\footnotetext{
${ }^{19}$ We are grateful to Louis Kaplow for this point.

${ }^{20}$ Since we have calculated the first and second derivatives of $\mathrm{Q}$, we could add higher order terms to this approximation, but since $\Delta P$ itself is an approximation that would be adding some second order terms and not others. The formula may be evaluated at pre-merger (in the spirit of Laspeyres) or post-merger (Paasche) quantities or an arithmetic (Marshall-Edgeworth) or geometric (Fisher) average of the two.
} 
order approximation for the change in quantity, $\widehat{\Delta Q} \approx \frac{\partial Q}{\partial P} \widehat{\Delta P} \cdot{ }^{21}$ Again ignoring externalities and out-of-market effects, the additional deadweight loss from the price increase is the sum of the change in quantities multiplied by the absolute mark-ups:

$$
\Delta D W L \approx \Delta Q^{\mathrm{T}}(P-\mathrm{mc}) \approx\left(\frac{\partial Q}{\partial P} \widehat{\Delta P}\right)^{\mathrm{T}}(P-\mathrm{mc}) .{ }^{22}
$$

The mark-ups can be pre-merger, post-merger or some combination of the two; various approaches, such as normalizing by the value of the market, construct unit-free indices. It would also be natural to include (as an additional term) an expected change in fixed (or more generally infra-marginal) costs due to the merger as in Williamson (1968). ${ }^{23}$

\section{Profits}

Our approach gives a simple approximation for the expected change in profits post-merger. While these changes are not typically an object of regulatory concern, an assumption that these must be positive by the firms' revealed preference for merging may provide some information. $^{24}$ If $\Delta F_{i}$ is the (presumably negative) change in firm $i$ 's fixed costs and $\Delta \mathrm{mc}_{i}$ is the (uniform) change inframarginal costs then

$$
\Delta \pi_{i} \approx\left(\Delta P_{i}-\Delta \mathrm{mc}_{i}\right)^{\mathrm{T}} Q_{i}+\left(P-\mathrm{mc}_{i}\right)^{\mathrm{T}}\left(\frac{\partial Q}{\partial P} \widehat{\Delta P}\right)-\Delta F_{i}
$$

The incentive for firms $i$ and $j$ to merge is just $\Delta \pi_{i}+\Delta \pi_{j}$.

\section{Advantages of Normative Analysis}

Estimating a unified, normatively significant quantity, such as the impact on consumer welfare, may offer several benefits over simply estimating a group of price effects. First, while in some cases it is possible to find remedies addressing particular areas of concern without impacting others, often a package of impacts are inherently tied to one another and must be evaluated as a whole. Such issues are particularly severe in the (quite common) case of mergers between firms with a large number of products that while not identical are broadly thought to compete in the same market. It may frequently be the case that some of these products' prices are predicted to rise (or rise by a large amount) and others to fall (or rise only slightly) after a merger. When making a decision in such a case it is necessary to aggregate all relevant information. Such an aggregation requires some implicit or explicit normative standard; welfare criteria are the natural choice, intuitively putting the greatest weight on the products with the largest market.

Additionally, many of the potential benefits and harms of a merger may arise through channels different from or only indirectly related to a change in price. One example is

\footnotetext{
${ }^{21}$ In many cases, such as consistent conjectures, the full Slutsky matrix is not necessary.

${ }^{22}$ Using the tax inclusive price includes tax revenue in social surplus in the spirit of Kaplow (2004).

${ }^{23}$ See Section VI.A below for a discussion of changes in marginal cost.

${ }^{24}$ We do not further explore this avenue here; another natural direction for future research to take such a formula is generalizing Deneckere and Davidson (1985)'s analysis of the incentives for a merger.
} 
consumption externalities (viz. network or platform effects): in an industry with advertisingfunded media, a primary harm from elevated prices to readers may be the reduction in the readership accessible to advertisers. Accounting for such harms requires a means of making them commensurate with typical price harms. Welfare-based standard makes this straightforward, as illustrated by White and Weyl (2011), who provide a simple extension of our formula to allow for network externality-based benefits and harms in a general framework. The comparative advantages of such a normative framework seem likely to only become greater when more complex effects - such as innovation, the dynamic price paths in an industry, and so forth - are taken into account. Such effects are typically considered entirely separately from simple price effects; in our framework, by contrast, it would be natural to simply extend the formula to include such effects whenever estimates or guesses as to their welfare effects are available.

\section{Extensions and Applications}

In this section we discuss implications of our results for applied merger analysis. While we have highlighted ways in which our approach combines many of the benefits of other approaches, this balancing clearly comes at some cost: direct use of the formulae we derive, while conceptually simple, would require many more inputs than the simple calculation of UPP. In this section, we illustrate how one might go about applying our approach in practice.

\section{A Marginal cost efficiencies}

The GePP formula derived above assumes no cost effeciencies generated by the merger and as such can be seen as the baseline case. However, if estimates of expected efficiencies are available, they can easily be incorporated. If post-merger firm $i$ 's marginal costs are expected to be $\widetilde{\mathrm{mc}}_{i}$, then the GePP for firm $i$ after a merger of firms $i$ and $j$ is

$$
\tilde{g}_{i}(P)=\tilde{D}_{i j}\left(P_{j}-\widetilde{\mathrm{mc}}_{j}\right)-\Delta\left(\left(\frac{d Q_{i}^{-1}}{d P_{i}}\right)^{\mathrm{T}}\right) Q_{i}-\left(\mathrm{mc}_{i}-\widetilde{\mathrm{mc}}_{i}\right) .
$$

This adjusted GePP can be used in the calculation of consumer or social surplus effects or to calculate the generalized version of Werden (1996)'s "compensating marginal cost reductions." For the marginal cost reductions to counterbalance the other incentive effects and lead to no price change, it must be that

$$
\left(\begin{array}{c}
\tilde{g}_{i}(\sigma) \\
\tilde{g}_{j}(\sigma)
\end{array}\right)=0
$$

which yields that compensating cost reductions of

$$
\left(\begin{array}{c}
e_{i}^{\star} \\
e_{j}^{\star}
\end{array}\right) \equiv\left(\begin{array}{c}
\mathrm{mc}_{i} \\
\mathrm{mc}_{j}
\end{array}\right)-\left(\begin{array}{c}
\widetilde{\mathrm{mc}}_{i} \\
\widetilde{\mathrm{mc}}_{j}
\end{array}\right)=\left(\begin{array}{cc}
\mathcal{I} & -\tilde{D}_{i j} \\
-\tilde{D}_{j i} & \mathcal{I}
\end{array}\right)^{-1}\left(\begin{array}{c}
g_{i}(\sigma) \\
g_{j}(\sigma)
\end{array}\right) .
$$

which simplifies to Werden's formula in the case of single-product Bertrand. Alternatively, if one wishes to apply the natural generalization of Farrell and Shapiro (2010a)'s more 
permissive standard, the off diagonal terms are ignored and the GePP itself is contrasted to (assumed default) efficiencies.

\section{B Simplifying the formula}

While it seems that UPP is, in some sense, a simpler calculation than those we suggest, this is simply because a UPP-based calculation imposes simplifying assumptions. For example, if we were to assume all firms produced a single product, that conduct were Bertrand, that all cross-product pass-through rates were zero, then our formula would simplify to $\sum_{i} Q_{i} \rho_{i} U P P_{i}$, where $\rho_{i}$ is the own-pass-through rate of each product.

Of course this is a very extreme example, but the general point is that beginning with our formula there are numerous simplifying assumptions one might make to reduce the complexity of the analysis. A few categories of assumptions one might consider are:

1. Pass-through: one could assume all cross pass-through rates (across firms and/or within particular products of a given firm) are zero so that we can ignore the impact of change in one merging firm's (opportunity) cost on the price of the other's product. One could impose symmetry on own- and cross- pass-through rates or, through an assumption akin to the horizontality assumption discussed in Subsection IV.B, assume some general relationship between pass-through rates and elasticities. Any of the assumptions discussed in Section IV above would aid in the identification of passthrough rates and might be useful when cross pass-through rates are too difficult to estimate.

2. Heterogeneity: imposing some form of symmetry, either between the two merging firms, among all non-merging firms, between the merging and non-merging firms or all of the above would simplify the equations. Alternatively, one could summarize all non-merging firms into a single firm. ${ }^{25}$ Any of these would greatly reduce the number of parameters to be estimated and thus reduce the data burden. Just the imposition of Slutsky symmetry across products would somewhat reduce the number of parameters.

3. Conduct: an assumption such as Bertrand, Cournot, or consistent conjectures would simplify implementation. Each of these is likely to be useful in different situations. For example, when consumer survey data or data based on "next favorite alternatives" from the internet are available, oligopoly models without flexible conjectures may be useful as such survey data directly reflects demand patterns. If cost shocks are available, consistent conjectures may be useful as an assumption as it reduces the number of independent instruments needed as discussed in Subsection II.C. If internal documents about firm expectations are available, a more flexible conjectural variations model may offer a more convenient form.

Given time and judicial constraints, some potentially unattractive assumptions will inevitably be imposed. Certainly, the full force of our general formula is only likely to be used in exceptional cases. However, our general formulation allows easy selection and application

\footnotetext{
${ }^{25}$ See Appendix D for an example.
} 
of any combination of assumptions - it does not force all industries into one mold. Furthermore, it is easy to conduct GePP analysis under several combinations of assumptions, facilitating the comparison of the resulting conclusions and thus clarifying the exact role each of these assumptions plays. This makes much clearer the robustness (or weakness) of results in any specific case.

\section{Approximateness}

While are approach only claims to approximate the effects of mergers, we want to emphasize that this is a direct result of sparsity of assumptions we make. If one were to assume a functional form for demand, that would generate all the higher order terms for the Taylor expansion and yield a precise result. However, in practice, such assumptions typically restrict important quantities, such as pass-through rates and elasticities (Crooke et al., 1999; Weyl and Fabinger, 2009). We understand that pass-through can be very difficult to measure, but we believe that using any information available or being explicit about what it is assumed to be is preferable to indirectly constraining it via functional form assumptions. Furthermore, the robustness of results to differing functional form, cost-side, or conduct assumptions can easily be examined without building a new computational model by simply changing some of the numbers that enter the relevant matrices.

\section{At which stage should our tools apply?}

Merger review typically proceeds in stages, beginning with an initial screen, proceeding through a more thorough investigation if the screen indicates danger and, if no settlement can be reached, proceeding to a full court case. As Werden and Froeb (2011) emphasize, FOAM is typically touted as appropriate as an initial screen, with some value during an investigation, but inadequate for a thorough investigation or in-court proceedings where a detailed merger simulation will typically be more compelling.

An advantage of our approach is that it avoids a sharp distinction between these different phases. A version of the formula with many assumptions like those proposed in Subsection B above may be imposed initially to accommodate limited time and data. As more time and data become available these assumptions can gradually be relaxed and replaced with estimates from data or detailed intuitions. If network effects, product repositioning or other factors are thought to be important they may be incorporated into the analysis from the first stages (using extensions of our formula as described in Section V), initially in a highly restricted way and then, again, these restrictions may gradually be relaxed as the analysis progresses. Thus our approach aims to incorporate all of the standard stages of an analysis continuously into a unified framework.

\section{E Other applications}

While our focus has been almost exclusively on merger analysis, some of our results and approach may apply to problems beyond this narrow context. Our approach to first-order approximation illustrates how local approximations may be used even in analyzing interventions that may at first blush seem discrete or discontinuous. Of course, this is valid only 
when the intervention is in some relevant sense small. However, there are many cases of interest, at least in industrial economics, when an intervention (such as the introduction of a new product or the entry of a new firm) may have only a small impact on consumer welfare and the prices of other products even though it may seem to constitute a discrete change. In these cases, our technique allows the sufficient statistics or first-order identification approach advocated by Chetty (2009) and Weyl (2009) to be applied more broadly than was originally envisioned.

\section{Conclusion}

In this paper, we extend the modeling framework of Telser (1972) to allow multi-product firms and price-choosing. We then analyze the framework to quantify, in this general setting, the incentive to change prices created by a merger. Next, we illustrate how first-order approximations may be applied to apparently discontinuous events such as mergers and used, with pass-through rates, to predict the approximate quantitative effects of mergers on prices. We then show how changes in prices may be given genuine welfare interpretations using standard approaches to price indices. We hope that this analysis will be directly useful in the formulation of future guidelines for merger evaluation and in the interpretation of those already in place.

We also hope to stimulate further work in this direction. Perhaps the simplest and most natural extension of our analysis, currently being undertaken systematically by several Department of Justice economists (Miller et al., 2011), would be to conduct a more broad ranging quantitative analysis of the accuracy of the first-order approximation for various demand and cost systems. Another step would be to consider an actual second-order approximation to the merger effect, with a focus on what variation would be needed to identify such an approximation and its intuitive interpretation.

On the more ambitious theoretical side, it will be important going forward to allow for dynamics: both to allow for dynamic time paths of adjusting prices and to incorporate effects like entry and and product repositioning typically studied in dynamic contexts. Such an analysis might either proceed through an explicit dynamic model, which might be amenable to first-order analysis only with substantially new techniques, or through the application of some form of Marshallian long-run analysis, which might be more directly connected to our analysis here. In a similar spirit, we only consider the unilateral effects of a merger: the change in incentives holding fixed the strategy space and conjectures. It would be natural to add coordinated effects, changes in the strategy space and conjectures, using a more explicit model of dynamic coordination. The incorporation into our model of non-Jevons effects on consumer welfare, such as those arising when firms choose quality or prices affect network size, is an active area of research being pursued by White and Weyl (2011) and Gaudin and White (2011).

Empirical work oriented towards measuring pass-through rates and how they vary across markets will be crucial in helping to calibrate policymakers' intuitions about these important, but often difficult-to-measure parameters. Similarly, work on understanding the empirical relationship between pre-merger, post-merger and merger pass-through rates will be important. Such work will help policy makers determine reasonable simplifying assumptions 
that can safely be made without sacrificing too much accuracy. The formulation of such simplifications is central to making the work here directly relevant to the often severely time-constrained analysis of particular mergers. 


\section{Appendix}

\section{A Deriving GePP}

Proof of Proposition 1. Writing $Q_{i}$ for $Q_{i}(P)$ for conciseness, the firm's first order conditions are

$$
Q_{i}+\left(\frac{\partial Q_{i}}{\partial \sigma_{i}}+\frac{\partial Q_{i}^{\mathrm{T}}}{\partial P_{i}} \frac{\partial P_{i}}{\partial P_{i}}\right)\left(P_{i}-\mathrm{mc}_{i}\left(Q_{i}\right)\right)=0
$$

Remembering that $\frac{d Q}{d P_{i}}=\frac{\partial Q}{\partial P_{i}}+\left(\frac{\partial Q}{\partial P_{-i}}\right)^{\mathrm{T}} \frac{\partial P_{-i}}{\partial P_{i}}$, and then multiplying by $-\left(\frac{d Q_{i} \mathrm{~T}}{d P_{i}}\right)^{-1}$ the firm's first-order conditions can be rewritten as:

$$
f_{i}(P) \equiv-\left(\frac{d Q_{i}^{\mathrm{T}}}{d P_{i}}\right)^{-1} Q_{i}-\left(P_{i}-\mathrm{mc}_{i}\left(Q_{i}\right)\right)=0 .
$$

After a merger of firms $i$ and $j$, the newly formed firm takes into account the effect of $P_{i}$ on $\pi_{j}$ and no longer expects $P_{j}$ to react to $P_{i}$ since the two are chosen jointly. The merged firm's first-order derivatives with respect to $P_{i}$ can be written:

$$
\begin{aligned}
h(P)=-\left(P_{i}-\mathrm{mc}_{i}\left(Q_{i}\right)\right)-\left(\frac{d Q_{i}^{\mathrm{T}}}{d P_{i}}\right. & \left.-\frac{\partial Q_{i}}{\partial P_{j}} \frac{\partial P_{j}}{\partial P_{i}}\right)^{-1} Q_{i} \\
& -\left(\frac{d Q_{i}{ }^{\mathrm{T}}}{d P_{i}}-\frac{\partial Q_{i}}{\partial P_{j}} \frac{\partial P_{j}}{\partial P_{i}}\right)^{-1}\left(\frac{d Q_{j}}{d P_{i}}-\frac{\partial Q_{j}}{\partial P_{j}} \frac{\partial P_{j}}{\partial P_{i}}\right)^{\mathrm{T}}\left(P_{j}-\mathrm{mc}_{j}\left(Q_{j}\right)\right),
\end{aligned}
$$

where the last term equals $\tilde{D}_{i j}\left(P_{j}-m c_{j}\left(Q_{j}\right)\right)$. Using the definition $g(P)=h(P)-f(P)$, we have:

$$
g_{i}(P)=\tilde{D}_{i j}\left(P_{j}-m c_{j}\left(Q_{j}\right)\right)-\left(\left({\frac{d Q_{i}}{d P_{i}}}^{\mathrm{T}}-\frac{\partial Q_{i}}{\partial P_{j}} \frac{\partial P_{j}}{\partial P_{i}}\right)^{-1}-\left(\frac{d Q_{i}^{\mathrm{T}}}{d P_{i}}\right)^{-1}\right) Q_{i}
$$

\section{B Cournot}

In this appendix we provide a general formula for GePP under Cournot competition and discuss pass-through in our simple symmetric, merger to monopoly example. In a (differentiated products) Cournot equilibrium each firm takes competitors' quantities as fixed. Instead of thinking of each firm as setting quantity, we can think of it as setting price with the expectation that other firms will adjust their prices so as to keep their quantities fixed. Using single-product firms for simplicity, pre-merger we have the first-order condition

$$
Q_{i}+\frac{\partial Q_{i}}{\partial P} \frac{d P}{d P_{i}}\left(P_{i}-\mathrm{mc}_{i}\right)=0
$$

We have $\frac{d P_{i}}{d P_{i}}=1$ and can pin down $\frac{\partial P_{-i}}{\partial P_{i}}$ because

$$
\frac{\partial Q_{-i}}{\partial P_{i}}+\frac{\partial Q_{-i}}{\partial P_{-i}} \frac{d P_{-i}}{d P_{i}}=0
$$


which implies

$$
\frac{d P_{-i}}{d P_{i}}=-\frac{\partial Q_{-i}^{-1}}{\partial P_{-i}} \frac{\partial Q_{-i}}{\partial P_{i}}
$$

This gives us a pre-merger condition of

$$
f_{i}(P)=-\left(P_{i}-\mathrm{mc}_{i}\right)-\frac{Q_{i}}{\frac{\partial Q_{i}}{\partial P_{i}}-\frac{\partial Q_{i}}{\partial P_{-i}} \frac{\partial Q_{-i}}{\partial P_{-i}}-1 \frac{\partial Q_{-i}}{\partial P_{i}}}=0 .
$$

After the firms merger, firm $i$ starts taking firm $j$ 's price as given, so, following the same logic as above, the GePP is

$$
\begin{aligned}
g_{i}(P)= & -\underbrace{-\frac{\frac{\partial Q_{j}}{\partial P_{i}}-\frac{\partial Q_{j}}{\partial P_{-i j}} \frac{\partial Q_{-i j}}{\partial P_{-i j}}-1}{\partial P_{i}}-\frac{\partial Q_{i}}{\partial P_{-i j}} \frac{\partial Q_{-i j}}{\partial P_{-i j}}{ }^{-1} \frac{\partial Q_{-i j}}{\partial P_{i}}}_{\text {Diversion Ratio }}\left(P_{j}-\mathrm{mc}_{j}\right) \\
& -\underbrace{Q_{i}\left(\frac{1}{\frac{\partial Q_{i}}{\partial P_{i}}-\frac{\partial Q_{i}}{\partial P_{-i j}} \frac{\partial Q_{-i j}}{\partial P_{-i j}}-1} \frac{\partial Q_{-i j}}{\partial P_{i}}-\frac{1}{\frac{\partial Q_{i}}{\partial P_{i}}-\frac{\partial Q_{i}}{\partial P_{-i}} \frac{\partial Q_{-i}-1}{\partial P_{-i}} \frac{\partial Q_{-i}}{\partial P_{i}}}\right)}_{\text {End of Accommodating Reactions }} .
\end{aligned}
$$

Example 2 Continued. Note that post-merger-to-monopoly, the firm is just a multiproduct monopoly which we can think of as choosing prices. In the limit as the products become undifferentiated and beginning from symmetry, a unit tax on each of the two goods will them be passed through to increased prices at the pass-through rate facing the monopolist. Yet note that $\tilde{D}$, the diversion ratio, is always 1 as the goods are undifferentiated and thus any sales lost by one on the margin are picked up by the other as we saw above. Let the actual pass-through rate for this common cost shock (which must be the same cross products as within, given that products are homogeneous) post-merger be $\rho$; then by equation (8), which is valid so long as $\left(\frac{\partial h}{\partial P}\right)^{-1}$ is strictly negative definite

$$
0 \neq \rho=-\left[\left(\frac{\partial h}{\partial P}\right)_{11}^{-1}-\left(\frac{\partial h}{\partial P}\right)_{21}^{-1}\right]+\left[\left(\frac{\partial h}{\partial P}\right)_{11}^{-1}-\left(\frac{\partial h}{\partial P}\right)_{21}^{-1}\right]=0
$$

a contradiction. Thus it must be that $\left(\frac{\partial h}{\partial P}\right)^{-1}$ is not in fact strictly negative definite at symmetric prices and thus pass-through must locally be infinite. Thus, in the undifferentiated limit, the 0 value of GePP is misleading: the net effect any common cost shock will have on incentives will apparently be 0, but because pass-through is so large, this cancels out. Exact calculations of post-merger-tomonopoly (merger) pass-through away from the limit in the symmetric case are a simplification of the formula in Appendix $F$ and are available in their simplified form on request.

\section{Consistent conjectures}

Proof of Proposition 2. Equilibrium is given by $f(P, x)=0$ so by the implicit function theorem

$$
\frac{d P}{d x}=-\left(\frac{\partial f}{\partial P}\right)^{-1}\left(\begin{array}{c}
\frac{d f_{1}}{d x} \\
\frac{d f_{2}}{d x} \\
0
\end{array}\right)
$$


and thus by the chain rule

$$
\frac{d Q}{d x}=-\frac{\partial Q}{\partial P}\left(\frac{\partial f}{\partial P}\right)^{-1} \frac{\partial f}{\partial x}
$$

where $\frac{\partial f}{\partial x} \equiv\left(\begin{array}{c}\frac{d f_{1}}{d x} \\ \frac{d f_{2}}{d x} \\ 0\end{array}\right)$.

However note that, as discussed in Section IV of the text, if $t$ is a vector of specific taxes on each of the goods

$$
\frac{d P}{d t}=-\left(\frac{\partial f}{\partial P}\right)^{-1} \quad \text { and } \quad \frac{\partial Q}{\partial t}=-\frac{\partial Q}{\partial P}\left(\frac{\partial f}{\partial P}\right)^{-1} .
$$

Thus, using the above formulae and letting the subscript on a vector 12 denote the sub-vector corresponding to the first two firms' entries and for a matrix consist of the principal submatrix formed by those to firms' row-column pairs,

$$
\left(\frac{d P_{12}}{d t_{12}}\right)^{-1} \frac{d P}{d t_{12}}=\left(\frac{d P_{12}}{d x}\right)^{-1} \frac{d P}{d x}
$$

where invertibility follows from the non-singularity of $\left(\begin{array}{l}\frac{d f_{1}}{d x} \\ \frac{d f_{2}}{d x}\end{array}\right)$ and $\frac{\partial f}{\partial P}$. Thus by the definition of consistent conjectures we have that

$$
\frac{d P}{d P_{12}}=\frac{d P}{d x}\left(\frac{d P_{12}}{d x}\right)^{-1}
$$

We wish to solve for

$$
\frac{d Q}{d P_{12}}=\left(\frac{\partial Q}{\partial P} \frac{d P}{d P_{12}}\right)_{12}=\left(\frac{\partial Q}{\partial P} \frac{d P}{d x}\left(\frac{d P_{12}}{d x}\right)^{-1}\right)_{12},
$$

but from the chain rule we have that $\frac{\partial Q}{\partial P} \frac{d P}{d x}=\frac{d Q}{d x}$ and thus

$$
\frac{d Q}{d P_{12}}=\left(\frac{d Q}{d x}\left(\frac{d P_{12}}{d x}\right)^{-1}\right)_{12}
$$

Breaking this up by row blocks yields $\frac{d Q}{d P_{1}}$ and similarly $\frac{d Q}{d P_{2}}$; breaking these resultant matrices down by columns yields the individual effects on $Q_{1}$ and $Q_{2}$. From this the desired pre-merger quantities are extracted and the post-merger quantities calculated as in the text. For example:

$$
\frac{d^{M} Q_{1}}{d P_{1}}=\frac{d Q_{1}}{d P_{1}}-\frac{d Q_{1}}{d P_{2}} \frac{d P_{2}}{d P_{1}}
$$

To establish that the result fails under Bertrand consider the simple linear demand system with $N$ firms given by

$$
Q=\alpha-\beta P
$$

where $\alpha$ is an $N$-dimensional vector, $\beta$ is an $N$-dimensional matrix with $N+\frac{(N-1) N}{2}=\frac{N(N+1)}{2}$ independent dimensions assuming Slutsky symmetry. Assume a constant marginal cost system $c$. 
Let $D_{\beta}$ be the diagonal matrix with the same diagonal entries as $\beta$. Then with single-product firms

$$
f=P-c-D_{\beta}^{-1} Q=P-c-D_{\beta}^{-1} \alpha+D_{\beta}^{-1} \beta P=\left[I+D_{\beta}^{-1} \beta\right] P-c-D_{\beta}^{-1} \alpha .
$$

Taking $c_{1}$ and $c_{2}$ as the exogenous variables for simplicity we can solve for equilibrium prices

$$
P=\left[I+D_{\beta}^{-1} \beta\right]^{-1} c+\left[I+D_{\beta}^{-1} \beta\right]^{-1} D_{\beta}^{-1} \alpha=\left[I+D_{\beta}^{-1} \beta\right]^{-1} c+\left[D_{\beta}+\beta\right]^{-1} \alpha
$$

and quantities

$$
Q=\left[I-\beta\left[D_{\beta}+\beta\right]^{-1}\right] \alpha-\beta\left[I+D_{\beta}^{-1} \beta\right]^{-1} c .
$$

Thus observing $\frac{d Q}{d c_{12}}$ and $\frac{d P}{d c_{12}}$ reveals the first two columns of $\left[I+D_{\beta} \beta\right]^{-1}$ and $\beta\left[I+D_{\beta}^{-1} \beta\right]^{-1}=$ $\left[\beta^{-1}+D_{\beta}^{-1}\right]^{-1}$. This places $4 N$ linear restrictions on $\beta$, but does not directly reveal the first two columns of $\beta$, which we wish to obtain, since under Bertrand $\frac{d Q}{d P}=-\beta$. For $N \geq 8,4 N<\frac{N(N+1)}{2}$ and thus the rank conditions for identification fail. Thus, in general under Bertrand identification does not hold. Note that typically, 8 firms are not necessary to ensure failure of Bertrand identification: it is only in this special linear case. More broadly, flexibility of second-order effects can cause failure even with only three firms.

\section{Conjectural variations examples}

Often, the two merging firms are closer competitors (and potential accommodators) with each other than with other firms in the industry. Therefore, we now consider a three firm model, with the two merging firms being symmetric but the third-firm being asymmetric, representing a reduced form for the rest of the industry. To keep things simple, though, we assume that the quantity of all firms $(q)$ and all firms' (Bertrand) demand slopes are the same, but now we have two diversion ratios: $d$, the (Bertrand) diversion to and from the third firm from and to each of the two merger partners and $\delta$, the diversion from each merger partner to the other. The mark-ups of the two merger partners are $m$. We assume that conjectures are in proportion to diversion: each merger partner anticipates an accommodating reaction of $\lambda \delta$ from its partner and $\lambda d$ from the third firm, while the third firm excepts $\lambda d$ from each of the merger partners.

Proposition 3. In the three-firm example, GePP from a merger of the two close firms is

$$
m \frac{\delta+\tilde{\lambda}\left(d^{2}-\delta^{2}\right)-\left(d^{2}+\delta^{2}\right) \frac{\tilde{\lambda}^{2}}{1-\delta \tilde{\lambda}}}{1-d^{2} \tilde{\lambda}} \approx m \frac{\delta+\tilde{\lambda}\left(d^{2}-\delta^{2}\right)}{1-d^{2} \tilde{\lambda}}
$$

where $\tilde{\lambda} \equiv \frac{\lambda}{1+\delta \lambda}$ and again the approximation is valid for small $\lambda$. Approximate GePP is thus increasing (decreasing) in $\lambda$ if and only if $d$ is greater (less) than $\frac{\delta}{\sqrt{1+\delta}}$. Approximate GePP is constant in $\lambda$ if and only if $d=\frac{\delta}{\sqrt{1+\delta}}$. Precise GePP decreases in strictly more cases than does approximate GePP.

If the strength of the within-merger interaction is small compared to that outside the merger, GePP increases with anticipated accommodation. Conversely, if the strength of within-merger interaction is sufficiently greater than the total outside interaction then accommodation decreases 
GePP. Some relevant cases may be close to the point where the degree of accommodation anticipated has little effect. To the extent that the effect of conduct on GePP is not too large, our general formulation becomes particularly useful because solution concepts such as consistent conjectures are more identifiable than are those standardly applied, as discussed in Subsection VI.C. Furthermore, it is reassuring for the theory of oligopoly that, even if the levels of prices may be quite sensitive to conduct, their comparative statics under interventions of interest may be less so.

Proof. Our proof here is almost entirely analogous to that of Example 3. The first-order condition now requires that for the merging firms

$$
m=-\frac{q}{\frac{\partial Q^{1}}{\partial P^{1}}\left(1-\left[d^{2}+\delta^{2}\right] \lambda\right)},
$$

so

$$
\frac{\partial Q^{1}}{\partial P^{1}}=-\frac{q}{m\left(1-\left[d^{2}+\delta^{2}\right] \lambda\right)} .
$$

On the other hand by the logic of conjectures discussed in the proof of Example 3 , if $l$ represents the pre-merger merging-firm-to-non-merging-firm conjecture, $L$ represents the same between the merging firms and $\tilde{l}$ represents the post-merger version of $l$ then

$$
l=\tilde{l}(1+L) \Longleftrightarrow \tilde{l}=\frac{l}{1+L} .
$$

Plugging in our definitions of $l=d \lambda$ and $L=\delta \lambda$ we obtain

$$
\tilde{l}=\frac{d \lambda}{1+\delta \lambda}
$$

Now we can compute

$$
\frac{d^{M} Q^{1}}{d P^{1}}=\frac{\partial Q^{1}}{\partial P^{1}}(1-\tilde{l} d)=-\frac{q\left(1-d^{2} \tilde{\lambda}\right)}{m\left(1-\left[d^{2}+\delta^{2}\right] \lambda\right)}
$$

and

$$
\frac{d^{M} Q^{2}}{d P^{1}}=-\frac{\partial Q^{1}}{\partial P^{1}}(\delta+\tilde{l} d)=\frac{q\left(\delta+d^{2} \tilde{\lambda}\right)}{m\left(1-\left[d^{2}+\delta^{2}\right] \lambda\right)},
$$

so that

$$
\tilde{D}_{12}=\frac{\delta+d^{2} \tilde{\lambda}}{1-d^{2} \tilde{\lambda}}
$$

while

$$
Q_{1}\left(\frac{1}{-\frac{d Q^{1}}{d P^{1}}}-\frac{1}{-\frac{d^{M} Q^{1}}{d P^{1}}}\right)=m\left(1-\frac{1-\left[d^{2}+\delta^{2}\right] \lambda}{1-d^{2} \tilde{\lambda}}\right)=m \frac{d^{2} \tilde{\lambda}-\left(d^{2}+\delta^{2}\right) \lambda}{1-d^{2} \tilde{\lambda}}
$$

And thus, with a little algebra, subtraction yields the formula in the text given that $\tilde{\lambda}-\lambda=\frac{\tilde{\lambda}^{2}}{1-\delta \tilde{\lambda}}$. Again, it can easily be verified, as before, that the more sophisticated formula is decreasing in $\lambda$ whenever the simpler version is, but also decreases in some cases (for larger $\lambda$ ) when the simpler version does not.

Returning to the simpler formula and taking the derivative with respect to $\lambda$ yields and expres- 
sion proportional to

$$
\left(d^{2}-\delta^{2}\right)\left(1-d^{2} \lambda\right)+d^{2}\left(\delta+\lambda\left[d^{2}-\delta^{2}\right]\right)=d^{2}(1+\delta)-\delta^{2},
$$

which is clearly positive or negative depending on the sign of the inequality in the proposition.

\section{E Taylor Series Error Term}

For notational convenience let $x=h^{-1}$. The error term is

$$
\begin{aligned}
\frac{1}{2}\left(\begin{array}{c}
\sum_{i} \sum_{j} \frac{\partial^{2} x_{1}}{\partial h_{i} \partial h_{j}} g_{i}\left(P^{0}\right) g_{j}\left(P^{0}\right) \\
\vdots \\
\sum_{i} \sum_{j} \frac{\partial^{2} x_{n}}{\partial h_{i} \partial h_{j}} g_{i}\left(P^{0}\right) g_{j}\left(P^{0}\right)
\end{array}\right) & =\frac{1}{2}\left[\sum_{i}\left(\begin{array}{ccc}
\frac{\partial^{2} x_{1}}{\partial h_{i} \partial h_{1}} & \cdots & \frac{\partial^{2} x_{1}}{\partial h_{i} \partial h_{n}} \\
\vdots & \ddots & \vdots \\
\frac{\partial^{2} x_{n}}{\partial h_{i} \partial h_{1}} & \cdots & \frac{\partial^{2} x_{n}}{\partial h_{i} \partial h_{n}}
\end{array}\right) g_{i}\left(P^{0}\right)\right] g\left(P^{0}\right) \\
& \equiv \frac{1}{2}\left[\sum_{i}\left(\frac{\partial^{2} x}{\partial h_{i} \partial h^{2}} g_{i}\left(P^{0}\right)\right)\right] g\left(P^{0}\right) .
\end{aligned}
$$

We know $\frac{\partial x}{\partial h} \frac{\partial h}{\partial x}=\mathcal{I}$. Differentiating with respect to $h_{i}$ gives:

$$
\frac{\partial^{2} x}{\partial h_{i} \partial h} \frac{\partial h}{\partial x}+\frac{\partial x}{\partial h}\left(\begin{array}{ccc}
\sum_{k} \frac{\partial^{2} h_{1}}{\partial x_{i} \partial x_{k}} \frac{\partial x_{k}}{\partial h_{i}} & \cdots & \sum_{k} \frac{\partial^{2} h_{1}}{\partial x_{n} \partial x_{k}} \frac{\partial x_{k}}{\partial h_{i}} \\
\vdots & \ddots & \vdots \\
\sum_{k} \frac{\partial^{2} h_{n}}{\partial x_{i} \partial x_{k}} \frac{\partial x_{k}}{\partial h_{i}} & \cdots & \sum_{k} \frac{\partial^{2} h_{n}}{\partial x_{n} \partial x_{k}} \frac{\partial x_{k}}{\partial h_{i}}
\end{array}\right)=0 .
$$

Solving for $\frac{\partial^{2} x}{\partial h_{i} \partial h}$, using $\frac{\partial x}{\partial h}=\left(\frac{\partial h}{\partial x}\right)^{-1}$ and substituting into (10) gives

$$
E=-\frac{1}{2} \sum_{i} \frac{\partial x}{\partial h}\left(\begin{array}{ccc}
\sum_{k} \frac{\partial^{2} h_{1}}{\partial x_{1} \partial x_{k}} \frac{\partial x_{k}}{\partial h_{i}} & \cdots & \sum_{k} \frac{\partial^{2} h_{1}}{\partial x_{n} \partial x_{k}} \frac{\partial x_{k}}{\partial h_{i}} \\
\vdots & \ddots & \vdots \\
\sum_{k} \frac{\partial^{2} h_{n}}{\partial x_{1} \partial x_{k}} \frac{\partial x_{k}}{\partial h_{i}} & \cdots & \sum_{k} \frac{\partial^{2} h_{n}}{\partial x_{n} \partial x_{k}} \frac{\partial x_{k}}{\partial h_{i}}
\end{array}\right) \frac{\partial x}{\partial h} g_{i}\left(P_{0}\right) g\left(P_{0}\right) \text {. }
$$

If we look at just the ath entry of the vector, we have

$$
\begin{aligned}
E & =-\frac{1}{2} \sum_{i} \sum_{j} \frac{\partial x_{a}}{\partial h_{j}}\left(\sum_{k} \frac{\partial^{2} h_{j}}{\partial x_{1} \partial x_{k}} \frac{\partial x_{k}}{\partial h_{i}} \cdots \sum_{k} \frac{\partial^{2} h_{j}}{\partial x_{n} \partial x_{k}} \frac{\partial x_{k}}{\partial h_{i}}\right) \frac{\partial x}{\partial h} g_{i}\left(P_{0}\right) g\left(P_{0}\right) \\
& =-\frac{1}{2} \sum_{i} \sum_{j} \frac{\partial x_{a}}{\partial h_{j}} \sum_{k} \sum_{l} \frac{\partial^{2} h_{j}}{\partial x_{l} \partial x_{k}} \frac{\partial x_{k}}{\partial h_{i}} \frac{\partial x_{l}}{\partial h} g_{i}\left(P_{0}\right) g\left(P_{0}\right) \\
& =-\frac{1}{2} \sum_{i} \sum_{j} \sum_{m} \sum_{k} \sum_{l} \frac{\partial x_{a}}{\partial h_{j}}\left(\frac{\partial x_{k}}{\partial h_{i}} \frac{\partial^{2} h_{j}}{\partial x_{l} \partial x_{k}} \frac{\partial x_{l}}{\partial h_{m}}\right) g_{i}\left(P_{0}\right) g_{m}\left(P_{0}\right) \\
& =-\frac{1}{2} \sum_{i} \sum_{j} \sum_{m} \frac{\partial x_{a}}{\partial h_{j}}\left(\frac{\partial x^{T}}{\partial h_{i}} D_{x}^{2} h_{j} \frac{\partial x}{\partial h_{m}}\right) g_{i}\left(P_{0}\right) g_{m}\left(P_{0}\right)
\end{aligned}
$$




$$
\begin{aligned}
& =-\frac{1}{2} \sum_{j} \sum_{m} \frac{\partial x_{a}}{\partial h_{j}}\left(\sum_{i} \frac{\partial x^{T}}{\partial h_{i}} g_{i}\left(P_{0}\right)\right) D_{x}^{2} h_{j} \frac{\partial x}{\partial h_{m}} g_{m}\left(P_{0}\right) \\
& =-\frac{1}{2} \sum_{j} \sum_{m} \frac{\partial x_{a}}{\partial h_{j}} g^{T}\left(P_{0}\right)\left(\frac{\partial x}{\partial h}\right)^{T} D_{x}^{2} h_{j} \frac{\partial x}{\partial h_{m}} g_{m}\left(P_{0}\right) \\
& =-\frac{1}{2} \sum_{j} \frac{\partial x_{a}}{\partial h_{j}} g^{T}\left(P_{0}\right)\left(\frac{\partial x}{\partial h}\right)^{T} D_{x}^{2} h_{j} \frac{\partial x}{\partial h} g\left(P_{0}\right) .
\end{aligned}
$$

Where $D_{x}^{2} h_{j}$ denotes the Hessian. Letting $[A]_{i j}$ indicate the $i j$ element of matrix $A$,

$$
E_{a}=-\frac{1}{2} \sum_{j}\left[\left(\frac{\partial h}{\partial x}\right)^{-1}\right]_{a j} g^{T}\left(P_{0}\right)\left(\left(\frac{\partial h}{\partial x}\right)^{\mathrm{T}}\right)^{-1}\left(D_{x}^{2} h_{j}\right)\left(\frac{\partial h}{\partial x}\right)^{-1} g\left(P_{0}\right) .
$$

Where the Hessian and derivatives are evaluated at some price in $\left[P^{0}, P^{M}\right]$.

\section{F Calculating $\frac{\partial g}{\partial P}$}

In the case of single product firms in a Bertrand equilibrium, we know that

$$
-\frac{\partial f(P)}{\partial P}=-\left(\begin{array}{cc}
2-\frac{Q_{i} \frac{\partial^{2} Q_{i}}{\partial P_{i}^{2}}}{\left(\frac{\partial Q_{i}}{\partial P_{i}}\right)^{2}} & \frac{\frac{\partial Q_{i}}{\partial P_{j}} \frac{\partial Q_{i}}{\partial P_{i}}-Q_{i} \frac{\partial^{2} Q_{i}}{\partial P_{i} \partial P_{j}}}{\left(\frac{\partial Q_{i}}{\partial P_{i}}\right)^{2}} \\
\frac{\partial Q_{j}}{\partial P_{i}} \frac{\partial Q_{j}}{\partial P_{j}}-Q_{j} \frac{\partial^{2} Q_{j}}{\partial P_{j} \partial P_{i}} & 2-\frac{\partial Q_{j}}{\left(\frac{\partial Q_{j}}{\partial P_{j}}\right)^{2}}
\end{array}\right)=\rho^{-1} \equiv-\left(\begin{array}{cc}
m_{1} & m_{2} \\
m_{3} & m_{4}
\end{array}\right) .
$$

Also,

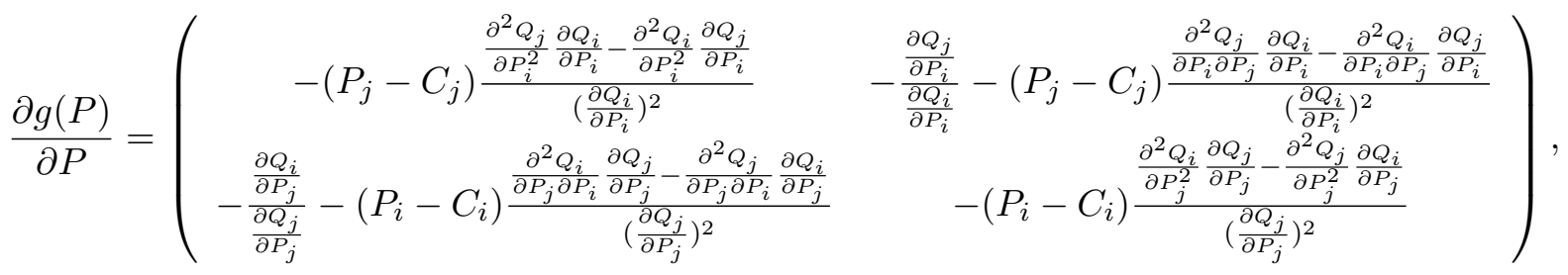

so, using Slutsky symmetry of $\frac{\partial^{2} Q_{j}}{\partial P_{i}^{2}}=\frac{\partial^{2} Q_{i}}{\partial P_{i} \partial P_{j}}$ and $\frac{\partial^{2} Q_{i}}{\partial P_{j}^{2}}=\frac{\partial^{2} Q_{j}}{\partial P_{i} \partial P_{j}}$, we have

$$
\frac{\partial g(P)}{\partial P}=\left(\begin{array}{ll}
v_{i} & v_{j}
\end{array}\right)
$$

where

$$
v_{i}=\left(\begin{array}{c}
-\frac{\left(P_{j}-C_{j}\right)\left(\frac{\partial Q_{i}}{\partial P_{j}} \frac{\partial Q_{i}}{\partial P_{i}}-m_{2}\left(\frac{\partial Q_{i}}{\partial P_{i}}\right)^{2}\right) \frac{\partial Q_{i}}{\partial P_{i}}-\left(\frac{\partial Q_{i}}{\partial P_{i}}\right)^{2}\left(2-m_{1}\right) \frac{\partial Q_{j}}{\partial P_{i}}}{Q_{i}\left(\frac{\partial Q_{i}}{\partial P_{i}}\right)^{2}} \\
-\frac{\frac{\partial Q_{i}}{\partial P_{j}}}{\frac{\partial Q_{j}}{\partial P_{j}}}-\frac{\left(P_{i}-C_{i}\right)\left(\left(\frac{\partial Q_{i}}{\partial P_{i}}-m_{2}\left(\frac{\partial Q_{i}}{\partial P_{i}}\right)^{2}\right) \frac{1}{Q_{i}} \frac{\partial Q_{j}}{\partial P_{j}}-\left(\frac{\partial Q_{j}}{\partial P_{i}} \frac{\partial Q_{j}}{\partial P_{j}}-m_{3}\left(\frac{\partial Q_{j}}{\partial P_{j}}\right)^{2}\right) \frac{1}{Q_{j}} \frac{\partial Q_{i}}{\partial P_{j}}\right.}{\left(\frac{\partial Q_{j}}{\partial P_{j}}\right)^{2}}
\end{array}\right),
$$




$$
v_{j}=\left(\begin{array}{c}
-\frac{\frac{\partial Q_{j}}{\partial P_{i}}}{\frac{\partial Q_{i}}{\partial P_{i}}}-\frac{\left(P_{j}-C_{j}\right)\left(\left(\frac{\partial Q_{j}}{\partial P_{j}}-m_{3}\left(\frac{\partial Q_{j}}{\partial P_{j}}\right)^{2}\right) \frac{1}{Q_{j}} \frac{\partial Q_{i}}{\partial P_{i}}-\left(\frac{\partial Q_{i}}{\partial P_{j}} \frac{\partial Q_{i}}{\partial P_{i}}-m_{2}\left(\frac{\partial Q_{i}}{\partial P_{i}}\right)^{2}\right) \frac{1}{Q_{i}} \frac{\partial Q_{j}}{\partial P_{i}}\right.}{\left(\frac{\partial Q_{i}}{\partial P_{i}}\right)^{2}} \\
-\frac{\left(P_{i}-C_{i}\right)\left(\frac{\partial Q_{j}}{\partial P_{i}} \frac{\partial Q_{j}}{\partial P_{j}}-m_{3}\left(\frac{\partial Q_{j}}{\partial P_{j}}\right)^{2}\right) \frac{\partial Q_{j}}{\partial P_{j}}-\left(\frac{\partial Q_{j}}{\partial P_{j}}\right)^{2}\left(2-m_{4}\right) \frac{\partial Q_{i}}{\partial P_{j}}}{Q_{j}\left(\frac{\partial Q_{j}}{\partial P_{j}}\right)^{2}}
\end{array}\right) .
$$

\section{References}

Ackerberg, Daniel, C. Lanier Benkard, Steven Berry, and Ariel Pakes, "Econometric Tools for Analyzing Market Outcomes," in James J. Heckman and Edward E. Leamer, eds., Handbook of Econometrics, Vol. 6B, North-Holland B.V.: Amsterdam, Holland, 2007. http: //www.economics.harvard.edu/faculty/pakes/files/tools81.pdf.

Baker, Jonathan B. and Timothy F. Bresnahan, "The Gains from Merger or Collusion in Product-Differentiated Industries," Journal of Industrial Economics, 1985, 33 (4), 427-444.

_ and _ , "Estimating the Residual Demand Curve Facing a Single Firm," International Journal of Industrial Organization, 1988, 6 (3), 283-300.

Berry, Stephen, James Levinsohn, and Ariel Pakes, "Automobile Prices in Market Equilibrium," Econometrica, 1995, 63 (4), 841-890.

Bowley, Arthur L., The Mathematical Groundwork of Economics, Oxford: Oxford University Press, 1924.

Bresnahan, Timothy F., "Duopoly Models with Consistent Conjectures," American Economic Review, 1981, 71 (5), 934-945.

Cabral, Luís M. B., "Conjectural Variations as a Reduced Form," Economics Letters, 1995, 49 (4), 397-402.

Carlton, Dennis W., "Revising the Horizontal Merger Guidelines," Journal of Competition Law and Economics, 2010, 6 (3), 619-652.

Chetty, Raj, "Sufficient Statistics for Welfare Analysis: A Bridge Between Structural and Reduced-Form Methods," Annual Review of Economics, 2009, 1, 451-488.

Cheung, Lydia, "The Upward Pricing Pressure Test for Merger Analysis: An Empirical Examination," 2011. http://www.econ.umn.edu/ cheun073/Cheung_JMP.pdf.

Ciliberto, Federico and Jonathan W. Williams, "Does Multimarket Contact Facilitate Tacit Collusion? Inference on Conjectural Parameters in the Airline Industry," 2010. http://papers.ssrn.com/sol3/papers.cfm?abstract_id=1657728.

Coate, Malcolm and Joseph Simons, "Critical Loss vs. Diversion Analysis?," CPI Antitrust Chronicle, 2009, 12 (1).

Commission, Competition and Office of Fair Trading, "Merger Assessment Guidelines," 2010. http://www.oft.gov.uk/shared_oft/mergers/642749/OFT1254.pdf. 
Crooke, Philip, Luke M. Froeb, Steven Tschantz, and Gregory J. Werden, "Effects of Assume Demand Form on Simulated Postmerger Equilibria," Review of Industrial Organization, 1999, $15(3)$.

Deneckere, Raymond and Carl Davidson, "Incentives to Form Coalitions with Bertrand Competition," RAND Journal of Economics, 1985, 16 (4), 473-486.

Dockner, Engelbert J., "A Dynamic Theory of Conjectural Variations," Journal of Industrial Economics, 1992, 40 (4), 377-395.

Farrell, Joseph and Carl Shapiro, "Horizontal Mergers: An Equilibrium Analysis," American Economic Review, 1990, 80 (1), 107-126.

_ and _, "Antitrust Evaluation of Horizontal Mergers: An Economic Alternative to Market Definition," Berkeley Electronic Journal of Theoretical Economics: Policies and Perspectives, 2010, 10 (1), Article 9.

_ and _, "Recapture, Pass-Through and Market Definition," Antitrust Law Journal, 2010, 76 (3), 585-604.

- and Michael L. Katz, "The Economics of Welfare Standards in Antitrust," Competition Policy International, 2006, (2), 3-28.

Froeb, Luke M., Steven Tschantz, and Gregory J. Werden, "Pass-Through Rates and the Price Effects of Mergers," International Journal of Industrial Organization, 2005, 23 (9-10), 703-715.

Gabaix, Xavier, David Laibson, Deyuan Li, Hongyi Li, Sidney Resnick, and Caspar G. de Vries, "Extreme Value Theory and the Equilibrium Prices in Large Economies," 2009. http://pages.stern.nyu.edu/ xgabaix/papers/CompetitionEVT.pdf.

Gandhi, Amit, Luke Froeb, Steven Tschantz, and Gregory J. Werden, "Post-Merger Product Repositioning," Journal of Industrial Economics, 2008, 56 (1), 48-67.

Gaudin, Germain and Alexander White, "Insulated Quality Competition," 2011. This paper is in preparation. Email Alex White at alexanderwhite@fas.harvard.edu for notes.

Hausman, Jerry, Serge Moresi, and Mark Rainey, "Unilateral Effects with General Linear Demand," 2010. http://econ-www.mit.edu/files/5926.

Herfindahl, Orris C., "Concentration in the U.S. Steel Industry," 1950. Columbia University.

Hirschman, Albert O., National Power and the Structure of Foreign Trade, Berkeley: University of California Press, 1945.

Jaffe, Sonia and E. Glen Weyl, "Linear Demand Systems are Inconsistent with Discrete Choice," Berkeley Electronic Journal of Theoretical Economics: Advances, 2010, 10 (1), Article 52.

_ and _ , "Price Theory and the Merger Guidelines," CPI Antitrust Chronicle, 2011, 3 (1). 
$\begin{array}{ccccccc}\text { and } & \text { Scott } & \text { Duke } & \text { Kominers, "Discrete Choice Cannot } & \text { Gen- } \\ \text { erate Demand that is Additively Separable in Own-Price," } & 2011 .\end{array}$ http://soniajaffe.com/articles/Jaffe_Kominers_Additive_Separability.pdf.

Kaplow, Louis, "On the (Ir)Relevance of Distribution and Labor Supply Distortion to Government Policy," The Journal of Economic Perspectives, 2004, 18 (4), pp. 159-175.

_ , "Why (Ever) Define Markets?," Harvard Law Review, 2010, 124 (2).

Kominers, Scott Duke and Carl Shapiro, "Second-order Critical Loss Analysis," 2010. This paper is in preparation.

Levy, David T. and James D. Reitzes, "Anticompetitive Effects of Mergers in Markets with Localized Competition," Journal of Law, Economics and Organization, 1992, 8 (427-440).

Majumdar, Adrian, Benoît Durand, Chris Doyle, and Alan Crawford, "Conjectural Variations and Competition Policy: Theory and Empriical Techniques," Technical Report, United Kingdom Office of Fair Trading 2011.

Mazzeo, Michael J., "Product Choice and Oligopoly Market Structure," RAND Journal of Economics, 2002, 33 (2), 221-242.

Miller, Nathan H., Marc Remer, Conor Ryan, and Gloria Sheu, "Assessing the Accuracy of Merger Approximation," 2011. This paper is in preparation. Contac the authors for an abstract and preliminary results.

Mirrlees, J. A., "An Exploration in the Theory of Optimum Income Taxation," Review of Economic Studies, 1971, 38 (2), 175-208.

Nevo, Aviv, "Identification of the Oligopoly Solution Concept in a Differentiated-Products Industry," Economics Letters, 1998, 59 (3), 391-395.

_ , "Mergers with Differentiated Products: The Case of the Ready-to-Eat Cereal Industry," RAND Journal of Economics, 2000, 31 (3), 395-421.

Posner, Richard A., Antitrust Law, Chicago: University of Chicago Press, 1976.

Quint, Daniel, "Imperfect Competition with Complements and Substitutes," 2010. http://www.ssc.wisc.edu/ dquint/papers/quint-vertical-and-horizontal.pdf.

Rogerson, William P., "The First-Order Approach to Principal-Agent Problems," Econometrica, 1985, 53 (6), 1357-1367.

Schmalensee, Richard, "Should New Merger Guidelines Give UPP Market Definition?," CPI Antitrust Chronicle, 2009, 12 (1).

Shapiro, Carl, "Mergers with Differentiated Products," Antitrust, 1996, 10 (2), 23-30.

_ , "The 2010 Horizontal Merger Guidelines: From Hedgehog to Fox in Forty Years," Antitrust Law Journal, 2010, 77 (1), 701-759.

Stigler, George J., "A Theory of Oligopoly," Journal of Political Economy, 1964, 72 (1), 44-61. 
Telser, Lester G., Competition, Collusion and Game Theory, Chicago: Aldine-Atherton, 1972.

United States Department of Justice and Federal Trade Commission, "Horizontal Merger Guidelines," http://www.justice.gov/atr/hmerger/11248.htm 1982.

_ and _ , "Horizontal Merger Guidelines," http://www.justice.gov/atr/public/guidelines/hmg2010.html August 2010.

Walters, Chris, "Diversion Ahead! Approximation Diversion Ratios for Retail Chain Mergers," 2007. http://www.mmc.gov.uk/our_role/analysis/diversion_ratios.pdf.

Werden, Gregory J., "Section 7 of the Clayton Act and the Analysis of "Semihorizontal" Mergers," Antitrust Bulletin, 1982, 27 (1), 135-160.

_ , "Horizontal Mergers: Comment," American Economic Review, 1991, 81 (4), 1002-1006.

_, "A Robust Test for Consumer Welfare Enhancing Mergers Among Sellers of Differentiated Products," Journal of Industrial Economics, 1996, 44 (4), 409-413.

_ and Luke Froeb, "Choosing Among tools for Assessing Unilateral Merger Effects," 2011. http://ssrn.com/abstract=1804243.

_ and Luke M. Froeb, "The Effects of Mergers in Differentiated Products Industries: Logit Demand and Merger Policy," Journal of Law, Economics, and Organization, 1994, 10 (2), 407426.

_ and _ , "Unilateral Competitive Effects of Horizontal Mergers," in Pablo Buccirossi, ed., Handbook of Antitrust Economics, MIT Press, 2008, chapter 2, pp. 43-104.

Weyl, E. Glen, "Slutsky meets Marschak: the First-Order Identification of Multiproduct Monopoly," 2009. http://www.glenweyl.com.

_ and Michal Fabinger, "Pass-Through as an Economic Tool," 2009. http://www.glenweyl.com.

White, Alexander and E. Glen Weyl, "Imperfect Platform Competition: A General Framework," 2011. http://ssrn.com/abstract=1694317.

Williamson, Oliver E., "Economies as an Antitrust Defense: The Welfare Tradeoffs," American Economic Review, 1968, 58 (1), 18-36. 